Beard Emma (Orcid ID: 0000-0001-8586-1261)

Marsden John (Orcid ID: 0000-0002-1307-2498)

Brown Jamie (Orcid ID: 0000-0002-2797-5428)

\title{
Understanding and using time series analyses in addiction research
}

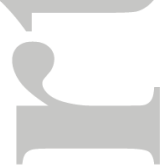

Emma Beard ${ }^{1,2}$, John Marsden ${ }^{3}$, Jamie Brown ${ }^{1,2}$, Ildiko Tombor ${ }^{2}$, John Stapleton ${ }^{1,3}$, Susan Michie 1, Robert West ${ }^{2}$

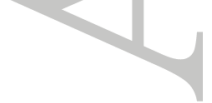

${ }^{1}$ Research Department of Clinical, Educational and Health Psychology, University College London, London

${ }^{2}$ Department of Behavioural Science and Health, University College London, London

${ }^{3}$ Addictions Department, Institute of Psychiatry, Psychology and Neuroscience, King's College London, United Kingdom;

Abstract: 181 words

Main text: 7114 words

Suggested running head: Time series analysis in addiction research

Keywords: time series, ARIMA, ARIMAX, VAR, SVAR, VECM, addiction

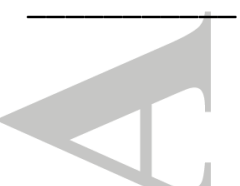

This article has been accepted for publication and undergone full peer review but has not been through the copyediting, typesetting, pagination and proofreading process which may lead to differences between this version and the Version of Record. Please cite this article as doi: 10.1111/add.14643

This article is protected by copyright. All rights reserved. 
* Corresponding author: Emma Beard, Senior Research Associate, Research Department of Clinical, Educational and Health Psychology, University College London, London; e-mail address: e.beard@ucl.ac.uk

\section{ABSTRACT}

Time series analyses are statistical methods used to assess trends in repeated measurements taken at regular intervals and their associations with other trends or events taking account of the temporal structure of such data. Addiction research often involves assessing associations between trends in target variables (e.g. population cigarette smoking prevalence) and predictor variables (e.g. average price of a cigarette) known as a multiple time series design, or interventions or events (e.g. introduction of an indoor smoking ban) known as an interrupted time series design. There are many analytical tools available, each with its own strengths and limitations. This paper provides addiction researchers with an overview of many of the methods available (GLM, GLMM, GLS, GAMM, ARIMA, ARIMAX, VAR, SVAR, VECM), and guidance on when and how they should be used, sample size determination, reporting, and interpretation. The aim is to provide increased clarity for researchers proposing to undertake these analyses concerning what is likely to be acceptable for publication in journals such as Addiction. Given the large number of choices that need to be made when setting up time series models, the guidance emphasises the importance of pre-registering hypotheses and analysis plans before the analyses are undertaken. 


\section{INTRODUCTION}

Time series analyses (TSA) are statistical methods for the analysis of multiple measurements of one or more variables over time. Sometimes these data reflect responses collected from a single research participant; but more commonly in social, behavioural and epidemiological research, TSA are used to study a variable of interest aggregated for a group, region or country. TSA can be a powerful tool for informing public health policy. There are comprehensive modules on TSA in statistical software (e.g. R and STATA) and several textbooks (1-4). TSA require the researcher to navigate a process of statistical modelling that requires a grasp of concepts, terminology and parameters that will be new to many in the addiction sciences.

This article provides an introduction to the topic, tailored to addiction research, setting out when it is appropriate to use each method and how to report and interpret findings. The paper is structured in four parts: Part 1 covers uses of TSA and how to plan the analyses; Part 2 focuses on TSA concepts and requirements; Part 3 looks at how to conduct TSA; and Part 4 describes how to report the results. For space reasons, we limit the article to the main TSA approaches that are supported by major statistical packages. The main types of analysis covered are: Generalised LeastSquares (GLS) and Generalised Linear Mixed Models (GLMM), Generalised Additive Mixed Models (GAMM), Autoregressive Integrated Moving Average (ARIMA) and Autoregressive Integrated Moving Average with Exogenous Variables (ARIMAX) models, Vector Autoregression (VAR) and Structural Vector Autoregressive models (SVAR), and Vector Error Correction Models (VECM).

\section{PART 1: USES OF TSA AND PLANNING THE ANALYSES}

Uses of TSA

There are several types of question that can be addressed by TSA. Simple 'trend analysis' assesses whether there is evidence for a change in the level of a series over time. For example, a study of first year college students used TSA to assess whether there was an increase in use of tobacco, alcohol and cannabis at the beginning and end of the academic year (5).

'Multiple TSA' assess whether a temporal trend in a target variable is linked to trends in other variables. In the smoking field, Beard et al examined whether the growth in prevalence of ecigarette use was linked to a decline in the use of licensed nicotine products such as nicotine skin patches (6). Langley et al assess the temporal association between a standardised measure of tobacco control advertising exposure on television and the number of calls to a national stop 
smoking helpline (7). Brunt et al assess the association between changes in the price and quality of cocaine and changes in the incidence of addiction treatment episodes and hospital admissions (8).

'Interrupted TSA' assess whether an event or shift in policy was associated with a change in the trend of a target variable. For example, Holder and Wagenaar studied changes in the rate of road traffic crashes after the introduction of a law on training for responsible alcohol-serving in licensed premises (9). An interrupted TSA was used to evaluate the effect on smoking prevalence of the partial tobacco point of sale display ban in large shops in England (10). Other studies have used interrupted TSA to evaluate: the impact on smoking cessation of temporarily suspending large-scale tobacco mass media campaigns (11); the introduction of the smoking cessation drug, varenicline, on prescribing of smoking cessation medications (12); the impact of introducing flexible alcohol trading hours on rates of violence, robbery and total crime (13); and changes in sale of alcohol following a ban on discounted alcohol products in shops and supermarkets (14).

TSA are also used in 'forecasting': projecting forward from past values of a series. For example, alcohol consumption over a prospective 10-year period was forecast for the Czech Republic (15). In the United States, age-specific mortality rates for men and women have been forecast using the decline in the prevalence of tobacco smoking (16).

\section{Data sources and design issues}

There are many suitable data sources for TSA, including official registries, repeated cross-sectional surveys and longitudinal studies of cohorts and panels. Examples include the Swiss HIV Cohort Study established in 1988 which continuously enrolled HIV-infected people who attended outpatient clinics at seven centres (17), and The Health Improvement Network (THIN) database in England $(18,19)$. TSA can be difficult to use in cohort and panel samples because of follow-up attrition (20), but this situation is improving with the advent of mobile/smartphone technologies (21-23).

At an individual level, data can be used from multiple repeated measurements from individuals in n-of-1 studies. For example, ecological momentary assessment generates large quantities of data from individuals (24) and digital mobile applications similarly can generate time series on usage, inputs, processes and outcomes (25).

In multiple TSA the coefficient linking a given input series to an output series can be interpreted as the association between the input and output series after adjusting for or removing any underlying trend and other input series included in the analysis. In interrupted TSA, a 'dummy' variable (taking 
the value 0 or 1 ) is used in the input series to reflect time points when events occur, or pre-versus post-initiation of a policy etc. The resulting coefficient can be interpreted as the change in the value or trend of the outcome variable linked to the presence or onset of the event or policy after adjusting for or removing any underlying trend and other input variables (11). TSA can be used with many types of data, including counts and percentages (e.g. number of heroin users arrested, the number of fatal drug-related poisoning cases, and the prevalence of adult smoking), binary data and continuous measures (e.g. amount spent on alcohol per week).

It is important to appreciate limitations of TSA. First, they can only assess associations at the temporal granularity of the series. Thus if the data are weekly, TSA are assessing week-by-week changes, not changes over a longer or shorter time frame. For example, showing an association between monthly spend on anti-tobacco mass media campaigns and attempts to stop smoking does not mean that a similar association would be found with annual spend. Secondly, TSA have limited ability to detect associations between input and output variables that accumulate over a long period. For example, anti-alcohol mass media campaigns may not have a detectable effect in the short term but may contribute to cultural change that accumulates over a period of years. Detecting such an effect would be very problematic for TSA.

\section{Sample size}

Statistical power calculations can inform study planning (26). Unfortunately, power calculations, such as those provided for linear regression and ANOVA in G*Power(27, 28), are not suitable for time series data. In TSA it is necessary to account for autocorrelation, seasonality and lag effects (see below). Calculations are provided by McLeod and Vingili $(29,30)$ for interrupted time series designs. However, the recommended method is to use a power simulation, and there are several statistical packages that can do this (e.g. R). The procedure involves running many TSA models on randomly generated data with expected parameter estimates and calculating power from the proportion of observations which return results at a given level of statistical significance.

In general, the sample size required will increase with the number of parameters to be estimated, and the amount of noise in the data. It is important to accurately reflect changes over time in the simulation and to include all covariate estimates of interest. There should always be more time points than the total number of variables, autocorrelation and lag terms and some experts recommend at least 50-100 time points (31-33). At least two years of monthly data has been proposed to allow adjustment for seasonality, with a preference for equal proportions of data collection before and after the event or change in the input variable for an interrupted TSA (26). 
Individual-level analyses generally provide greater power, and a larger number of observations aggregated to create each data point are likely to give more stable estimates (34).

\section{PART 2: TIME SERIES CONCEPTS}

The data for any TSA are typically partitioned into three main components: a trend component, a seasonal component and a random component (35). As an example, Figure 1 displays a hypothetical de-composition of data on the prevalence of excessive alcohol consumption over time (36 monthly waves of data collection).

The 'trend' chart in the top right-hand panel shows a plotted trend derived from observed data in the top left panel (using a 12-month two-point moving average). It appears that the prevalence declines in a roughly linear manner over time.

The 'seasonal' chart in the bottom left panel in Figure 1 shows a cyclical pattern derived from the data in the top left panel. We note that weekly seasonality can be modelled if the data are collected daily. This would reflect cyclical changes due to the day of the week (e.g. showing that more alcohol is consumed at the weekend).

The 'random' chart shows the component that represents unexplained variance. This represents any remaining variation in the series that is not accounted for by the trend and seasonality components.

\section{Underlying trends and stationarity}

To make inferences about the impact of the introduction of a policy or intervention or how two time series covary it is important to address any underlying long-term trends. This can be done either a) by systematically modelling the trend or b) removing it from the data. Screening a data series for an underlying trend is achieved by assessing the association between values and their position in the series.

Modelling of the underlying trend in a series can be accomplished by including a linear or polynomial term reflecting time points as an independent variable in a statistical model. Greater flexibility can be achieved with the use of fractional polynomials or what are known as 'restricted cubic splines'.

Removing any underlying trend involves transforming the data in some way to make it 'stationary' (stationary refers to a time series is one whose statistical properties such as mean, variance, 
autocorrelation, etc. are all constant over time).. There are several options for making a series stationary. First, one can remove a trend through 'differencing', which involves using the differences between observations rather than the observations themselves. A series of 'first differences' (subtract values at time $t$ from values at time $t+1$ ) will work to remove linear trends (36). 'Seasonal differencing' involves subtracting values from values that are a fixed number of time points ahead (e.g. taking values at $\mathrm{t}$ from values at $\mathrm{t}+12$ in monthly data).

In situations where there is evidence of a non-constant slope (e.g. an exponential trend), second differences (taking the first difference of the already differenced series) will often render the series stationary (37) In practice, it is almost never necessary to go beyond second differencing (36). However, if a series does exhibit higher degree polynomial trends, an order of differencing equal to that degree may be required (38).

There are several 'unit root' tests that can help determine the number of differences required for the time series to be made stationary. Two of the most commonly used of these are the augmented Dickey-Fuller (ADF) test and the Phillips Perron tests $(39,40)$.

Researchers should guard against over-differencing. To assess the presence of over-differencing, the autocorrelation of the differenced data should be calculated (see below). A rule of thumb is that the lag-1 autocorrelation should not be more negative than -0.5 (see section on autocorrelation for more details) (41).

Another way to address non-stationarity is to use natural logarithmic or square root transformations (38). Of the two, the natural logarithmic transformation is often preferred as it has the statistical property of converting absolute changes to percentage changes, which makes for easier interpretation of the outputs. The main priority here is to stabilise the variance of the underlying series. Failure to stabilise the variance can reduce forecasting precision and undermine accurate assessment of associations (42). It is often necessary to difference and transform a time series.

In the previous example of prevalence of excessive alcohol consumption, the ADF test suggested that one order of differencing was required with no seasonal differencing. Figure 2 shows a plot of the time series data for excessive alcohol consumption following a natural log transformation and first order differencing.

Autocorrelation

This article is protected by copyright. All rights reserved. 
There is autocorrelation within a series if values in the series are in some way statistically associated with earlier values. There are two main types of autocorrelation: autoregressive (AR) and moving average (MA). The former occurs when values in a series are correlated with earlier values. The latter occurs when values in a series are a function of the degree of prediction error of earlier values after taking account of any correlation between the values. For example, $A R(1)$ means that values of a series at one point in time are correlated with immediately preceding values. MA(1) means that values of a series are a function of the difference between the immediately preceding value and a predicted value (the error) from a regression of values on to immediately preceding values. In both cases the 'lag' is said to be one. Where the autocorrelations involve preceding values going further back from the current values, the lag value increases.

The degree of autocorrelation across a set of lags is called the autocorrelation function (ACF) and this plays a key role in model selection and evaluation. To determine which type of autocorrelation applies in a given case, the researcher checks the ACF and Partial ACF (PACF). The PACF shows autocorrelations between values at a point in time and the lagged values 1, 2, 3 etc in which correlations for higher lags are adjusted for correlations at lower lags.

As a rule of thumb, if the PACF displays a sharp cut-off (for example a large lag-1 autocorrelation but small lag autocorrelation and/or the lag-1 autocorrelation is positive), it is best to add an AR term. If the ACF displays a sharp cut-off and/or the lag-1 autocorrelation is negative, the addition of an MA term should be considered (43). For example, the ACF and PACF in Figure 3 suggest an MA and $A R$ autocorrelation term may be needed, as both cut off abruptly after a lag of 1 and 2 respectively.

\section{Lagged effects}

The effects of an intervention or event can be gradual or delayed. In these cases, lagged effects need to be considered in the analysis (34). For example, a hypothetical intervention may have been introduced in July 2008 but publicity campaigns were not implemented until two months later. In this instance one would model the impact of the intervention in July 2008 and the impact of the intervention assuming a delay in August 2008 and September 2008. Alternative models with varying lag effects can be compared using a measure of fit such as the Bayesian Information Criterion (BIC) or Akaike's Information Criterion (AIC(43)).

Lagged effects can also be encountered in multiple TSA. For example, monthly prevalence of smoking cessation may not immediately impact on alcohol consumption but may start to have an effect a month or two later (44). The presence of lags can be assessed using the same methods as 
for interrupted TSA or by using the sample cross correlation function (CCF). The CCF provides a set of sample correlations between the input series $(X)$ at time $t+h$ and the output series $(Y)$ at time $t$, where $\mathrm{h}$ can be any value reflecting past or future points of data collection. For example, the researcher may be interested in the effect on the output series $(Y)$ at month three of the input series $(\mathrm{X})$ two months prior i.e., $X_{3-2} \sim Y_{3}$ (3).

Generally, 'pre-whitened' data are used in conjunction with the CCF as this aids interpretation by removing autocorrelation in the series that may cause spurious cross-correlation effects. Prewhitening decorrelates the input series and then applies the same filter (autoregressive model) to the output series.

\section{Confounding}

Causality can generally be inferred from randomised controlled trials (i.e. where participants are randomly assigned to an intervention versus comparison group) and procedures are put in place to remove bias, such as blinding participants. Although causality can less confidently be inferred from observational research designs, an assessment can be done to determine how far causal inference is justified (e.g. using the Bradford Hill Criteria (45)). Whether the design is experimental or observational, it is important to consider, measure and adjust for potential confounding in TSA. At the individual level this may involve including socio-demographic characteristics; at the population level it may involve other interventions and policies that are being introduced in that population. These potential confounders should be pre-defined in the analysis plan.

\section{Outliers}

Outliers are values that are very different from the majority of those in a time series. Outliers can be problematic for TSA because they may exert a disproportionate influence on coefficient estimates (46). Outliers may be justifiably removed if they are determined to be errors and they fall at the start or end of the series.

One useful package is 'tsoutliers' in $\mathrm{R}$ which identifies and suggests possible replacement values by using an iterative outlier detection approach descibed by Chen and Liu $(47,48)$. However, this procedure may misidentify a valid shift in level as an outlier or fail to detect outliers due to masking (49). If outliers are removed it is important to run and report a sensitivity analysis with their inclusion (50). The procedure for detecting and removing outliers should be pre-specified in the statistical analysis plan to reduce risk of researcher bias. 


\section{Missing data}

Missing data present major problems for TSA. If TSA are being conducted on aggregated data from surveys or cohorts and these have differing amounts and types of missing data in the samples generating the aggregate value, any temporal changes may reflect this 'missingness' rather than anything real in the population.

If data for particular time points are completely missing, TSA cannot be undertaken unless assumptions are made to impute those missing values. 'Last observation carried forward' or 'mean subtitution' are sometimes used but may create bias (51). This is especially true for multiple TSA where there are additional levels of complexity in the form of lagged relationships and autocorrelations that need to be accounted for.

An alternative is multiple imputation. This proceeds by predicting missing data with plausible values to create multiple completed datasets and then applying standard complete-data procedures to each one and combining the results (52). Several multiple imputation packages designed for time series data are available. The multiple imputation package 'Amelia' in R works by directly adding lags and time, and its polynomials, as covariates (53). Other R packages for multivariate data include MICE (54) and VIM (55). Several methods have also been proposed for univariate series (56) including 'imputeTS' (57).

\section{PART 3: SELECTING AN ANALYSIS MODEL}

There are numerous statistical methods that can be used to analyse time series data. The choice of method depends on the study design, the research question and the number of input and output series. We provide $\mathrm{R}$ code for the analyses specified below (Appendix 1 in the Supplementary File).

\section{Generalised Linear Models and Linear Regression}

In the absence of autocorrelation, generalised linear models (e.g. Poisson regression for low frequency rate data and logistic regression for binary data) and linear regression (including its variants polynomial regression, power and logarithmic regression) can be applied if there is interest in descriptive or explanatory modelling by regressing an output series $(y)$ on to a time trend:

$$
y_{t}=\beta_{0}+\beta_{1} \text { trend }
$$

If the TSA question is the impact of an event or intervention, a 'segmented (or piecewise) regression' can be used by adding two additional terms: 1) a variable reflecting the introduction of the 
intervention (e.g. a dummy variable coded for before the event [0] and after [1]) and 2) a variable reflecting the change in slope following the intervention (e.g. a variable coded for before the event [0] and after [1...n], where $\mathrm{n}$ is the total number of time points to the end of the series):

$$
y_{t}=\beta_{0}+\beta_{1} \text { trend }+\beta_{2} \text { level }_{t}+\beta_{3} \text { slope }+e_{t}
$$

An alternative specification commonly used is as follows:

$$
y_{t}=\beta_{0}+\beta_{1} \text { trend }+\beta_{2} \text { level }_{t}+\beta_{3}[\text { trend } \times \text { level }]+e_{t}
$$

In this case, $\beta_{1}$ represents the underlying pre-intervention trend, $\beta_{2}$ is the level change following the intervention and $\beta_{3}$ indicates the slope change following the intervention. The prior specification is preferred as interaction terms can become complex, particularly if there is interest in estimating the mediation effect of other variables. Interpretation also often requires further data preparation, such as 'centering' (58).

If the question is how two time series co-vary, this can be assessed by including the input time series data $(\mathrm{x})$ as a continuous predictor variable. The regression model is specified as:

$$
y_{t}=\beta_{0}+\beta_{1} \text { trend }+\beta_{2} x+e_{t}
$$

Lag effects can be assessed by deriving a backward shifted variable and including this along with the original version in the model. This would specify the associations between past values of $x$ and current values of $y$ plus current values of $x$ and current values of $y$, whilst adjusting for each other. However, the analyses described below are preferred to test for lag effects because the inclusion of a backward shifted variable in the model can result in high collinearity of input variables.

To adjust for seasonality, four breakpoints can be used to reflect the four seasons or 12 to reflect each month. An alternative is to estimate discrete intercepts for each month (e.g. including dummy variables to represent each month), but this is often undesirable because the degrees of freedom are increased and power is reduced. Moreover, seasonal variation is more realistically represented in a smooth, continuous rather than discrete fashion. A smoother reflection of seasonality can be adjusted for by calculating a seasonal index which is an average of residuals for a given time period, and subtracting these from the data (59).

Natural 'cubic splines' can also be included in the regression model (60). A cubic spline consists of piecewise third-order polynomials - a set of cubic curves joined at break points. The choice between the seasonal index and natural cubic splines depends on whether seasonal effects are theoretically important, with the former being easier to interpret but the latter usually more likely to represent 
the underlying trend. It should be noted that to model monthly or weekly seasonality the time series must contain at least two cycles (i.e. two years for monthly seasonality or two weeks for daily seasonality). There are also other cyclical environmental factors that may need to be considered, such as temperature and weather (61).

\section{Generalised Least-Squares}

An extension of linear regression known as Generalised Least-Squares (GLS) can estimate a linear model at the individual or aggregated level while allowing possible unequal variances and correlations between error terms (62). GLS models have been successfully applied in the addictions field. For example, they have been used to estimate the association between alcohol consumption and mortality and liver cirrhosis rates $(63,64)$. GLS cannot be used with non-normally distributed data, and there can be inflated probabilities of Type 1 error when the covariance structure of the data is incorrectly specified (65).

\section{Generalised Linear Mixed Models}

For time series data with repeated observations on individuals in a sample, autocorrelation can be accounted for in a Generalised Linear Mixed Model (GLMM; also known as a hierarchical or multilevel model). A GLMM includes a random term with time nested within individuals, and with a covariance matrix consisting of AR and/or MA terms. Any misspecification of the covariance matrix can produce biased estimates (66).

Where there is uncertainty about the covariance matrix, an alternative approach is Generalised Estimating Equations (GEEs). GEEs treat the covariance matrix of responses as nuisance parameters and account for correlations using what are known as 'sandwich-type' variance estimates (66). It should be noted that GEEs have their own limitations and can only work at one level of clustering (67). GLMM and GEE are only suitable where data on individuals are being used to derive time series parameters at the population level (i.e. where there is clustering).

\section{Generalised Additive Models and Generalised Additive Mixed Models}

In recent years, there has been a move towards semi-parametric extensions of GLM and GLMM, called Generalised Additive Models or Generalised Additive Mixed Models (GAM and GAMM). The ideas behind these extensions are: 1) that seasonality is adjusted for using data driven smoothing 'splines' comprised of a series of knots (e.g. 12 knots for 12 months) which have been shown to yield regression coefficients and variance estimates that are less biased; 2) smoothing terms that 
can offer a flexible alternative to specifying polynomial time trend terms in GLM and GLMM and; 3) although GAMM allows clustering effects to be specified, there is no requirement for a grouping level, so it can be used with pre-aggregated data (68).

GAMM also has limitations, including increased computational demands for complex modelling (69, 70). This is particularly true for binary outcomes when 'penalised quasi-likelihood', an alternative to maximum likelihood when there is evidence of over-dispersion, is used to estimate parameters. Over-dispersion is the presence of greater variability in a data set than would be expected and its absence is a pivotal assumption for logistic and Poisson models. Quasi-likelihood models tend to underestimate the standard error of the fitted parameters for Poisson data with a mean number of counts of less than five (71). A number of recommendations have been given to improve computational performance issues, including the use of a Broyden-Fletcher-Goldfarb-Shanno (BFGS) optimiser and the use of grouping factors when specifying the correlation structure (71).

Autoregressive Integrated Moving Average (ARIMA)

Autoregressive Integrated Moving Average (ARIMA) refers to regression-based models that assume time series values are continuous or count-based measurements. These models are typically used to model the impact of an intervention and more accurately take account of autocorrelation by the inclusion of both seasonal and non-seasonal AR and MA terms $(72,73)$. ARIMA modelling is more flexible than GAMM for interrupted TSA because it allows the researcher to estimate whether changes in the output series pre-empted the intervention and whether these effects were transient or permanent. To achieve this, the input variables are entered as 'dummy' codes (either 1 or 0 depending on whether the intervention is hypothesised to be in operation or not). For example, if a pulse effect is hypothesised this would take values 0 before the intervention, 1 during the period where it is implemented, and 0 after the intervention.

ARIMA models are often denoted as $\operatorname{ARIMA}(q, d, p)$, where $q$ is the number of $A R$ terms, $d$ is the level of differencing and $p$ is the number of MA terms. If a seasonal model is to be specified, known as a seasonal ARIMA or SARIMA, then this is often denoted as ARIMA $(q, d, p)(Q, D, P) s$, where s reflects the seasonal order (e.g. 12 if monthly or 4 if quarterly), $Q$ is the seasonal AR terms, D seasonal differencing and $\mathrm{P}$ seasonal MA terms.

ARIMA models are affected by issues of non-linearity, multicollinearity and heteroscedasticity (43, 74). Violations of these assumptions underlying the model may be managed by data transformation, but this risks introducing bias and losing efficiency (75). Researchers can judge model fit with a variety of indicators including the $\mathrm{AIC}$ and $\mathrm{BIC}$ where the lowest values can point to the preferred 
number of lags and extent of AR and/or MA autocorrelation (35). The Ljung-Box test for white noise and ACF of the residuals of the best fitting models can also indicate whether additional terms are needed.

ARIMA models have the additional assumption that coefficients of the autocorrelation terms should contribute significantly to the model and fall within the bounds of stationarity and invertibility; i.e. the coefficient values for the autocorrelation terms should be $>1$ or $<1$ in total). This ensures that the series is stationary around its mean. For example, if two AR terms are included in a model with values of 0.5 and 1.1, this would violate the assumption. The solution would be to return to a simpler model with one AR term. As with GAMM and GLMM there are concerns regarding model misspecification and researchers are advised to use a variety of methods during model selection to inform decisions about parameter inclusion (e.g. the ACF, PACF, plots of residuals and AIC or BIC).

\section{Autoregressive Integrated Moving Average with Exogenous Variables (ARIMAX)}

Autoregressive Integrated Moving Average with Exogenous Variables (ARIMAX) is an extension of ARIMA that is particularly suited to undertaking multiple TSA: explaining changes in the value of an output data series as a function of current and prior values of one or more input series $(43,76)$. For example, it was recently used to assess whether changes in smoking prevalence had been associated with changes in the prevalence of high-risk drinking at a population level in England (44).

ARIMAX models have an additional assumption known as 'weak exogeneity' which specifies that there is no reverse causal pathway (i.e. $\mathrm{Y}$ can depend on the lagged values of $\mathrm{X}$, but not vice versa). This can be assessed with the Granger Causality test (77). Some argue that this test can also be used to support the claim that the input variable is having a causal effect on the output variable, but this is only the case if there are no other threats to a causal interpretation (78).

ARIMAX models have a major advantage over regression-based methods such as GLMM and GAMM because they explicitly include the effect of the occurrence order of the values in the series. For example, it is possible that both current and past smoking rates affect current levels of excessive alcohol consumption. ARIMAX models use chronological information contained in the time series through 'transfer functions' in which current and past values of an independent variable can both be used for prediction (79).

The major disadvantage of ARIMA and ARIMAX models is their inability to assess moderation effects. For example, researchers in a recent comparative analysis of the relationship between aggregate alcohol consumption and homicide rates in Russia and in the United States ran separate 
models for each country and compared the effects. They concluded that the role of alcohol in homicide seems to be larger in Russia than in the United States (80). However, they could not test the difference between the trends in the different regions directly.

If a stratified analysis approach is taken in lieu of a direct test of moderation effects, it is recommended that standardised coefficients are used to allow comparisons between groups. Results can then be interpreted in terms of standard deviations rather than original units. The fit of the different models (e.g. for each country) can also be compared using the AIC or BIC. Another solution may be the use of a Autoregressive Fractionally Integrated Moving Average (ARFIMA) and multilevel modeling (MLM) framework (ARFIMA-MLM) to estimate both individual and aggregated level effects (81). However, such models are generally only suitable when modelling long-run behaviour.

\section{Vector Autoregression}

Vector Autoregression (VAR) can be used for most multiple time series analysis and is preferred when causal relationships may be bi-directional. It captures linear interdependencies among multiple time series simultaneously, with one equation computed per variable. Each equation consists of a constant, a lag term which captures the influence of the lag of a variable on itself and the lag on the other variable(s), and an error component. Screening of each series for stationarity is done by unit root testing and autocorrelation is captured by lags, which are selected using the AIC or BIC. Evidence for Granger causality is then sought and the recommended model is fitted, and autocorrelation and normality among the residuals are assessed via the Jaques Barra test (82).

There are several rules of thumbs to help in the selection of the number of lags when running a VAR model. It has been suggested that the model should typically include enough lags to capture the full cycle of the data (e.g. 12 lags for monthly data). It should be expected that there will be a seasonality effect carried over from year to year and across the months, so greater series lengths may be necessary. Another rule of thumb, is that the lag length should not use up too many degrees of freedom (i.e. max lag $=\frac{t-1}{m}$, where $\mathrm{m}$ is the number of exogenous variables and $\mathrm{t}$ the number of observations). For example, a time series with 60 periods and three variables should not include more than about 20 lags (83). Interpretation of the results of a VAR can be difficult, particularly if there are large numbers of lags.

Orthogonalised Impulse Response Functions (OIRF) are usually plotted to assess how an event affects current and future values of one or more output variables. Figure 4 gives a graphical representation of the OIRF for a VAR model using simulated data to assess the association between 
smoking prevalence and prevalence of high-risk drinking. The OIRF shows the change in the prevalence of high-risk drinking in response to a change in smoking prevalence in the same month and in the subsequent months. The dashed blue line represents the estimate at different time lags, and the shaded area is the $95 \%$ confidence interval. The IRF suggests that there is an effect of smoking prevalence on high-risk drinking prevalence in the same period. A cumulative IRF can also be derived which shows the overall effect of an event (i.e. the total change in the response variable following a change in the input variable at different time lags).

\section{Structural Vector Autoregressive models}

VAR models only use the lags of one series and may therefore miss valuable information when 'instantaneous' causality is present (i.e. values in one variable influence values in another within the same observation period). As a solution, Structural Vector Autoregressive Models (SVAR) helps to model the temporal relationships between series and place restrictions so that relationships can be specified in a unidirectional manner. The analysis proceeds following the generation of stationary data with the specification of a matrix which contains parameter constraints. In simple two-series TSA the matrix is generally specified as:

$$
\left[\begin{array}{ll}
X \rightarrow X & Y \rightarrow X \\
X \rightarrow Y & Y \rightarrow Y
\end{array}\right]
$$

If the aim is only to assess the relationship from $X$ to $Y$, it is assumed that the effect of $X$ on $X$ and $Y$ on $Y$ is 1 , and the effect of $Y$ on $X$ is 0 . Therefore, the only parameter that needs to be estimated is $X \rightarrow Y$. This would be appropriate for a unidimensional model for the evaluation of tobacco and alcohol control policies when it can be assumed that causal relationships run from the policy to the outcome but not from the outcome to the policy.

As with VAR analysis, appropriate lags which account for the presence of autocorrelation can be assessed by comparing models using measures of goodness of fit (83). The output is also in the form of an impulse response function, which indicates how a change in the variable $X$ affects future values of Y. SVAR was used recently to evaluate the effect of tobacco control media campaigns and pharmaceutical company-funded advertising for nicotine replacement therapy on smoking cessation activity (7).

\section{Vector Error Correction Models}

VAR and SVAR models are not suitable in the presence of 'co-integrating relationships'. This phenomenon arises when two variables share a common trend, and the linear combination of the variables is stationary. For example, the number of cigarettes smoked per day and amount spent on 
cigarettes per day may both exhibit a downward trend over time. Because both series are driven by the same trend, the consumption/expenditure ratio will fluctuate about a constant mean i.e. the difference between series has no obvious trend. This is shown graphically in Figure 5. Co-integrating relationships can be addressed by re-parameterising the VAR/SVAR model as a Vector Error Correction Model (VECM).

The presence of co-integrated variables can be tested using the Johansen procedure (84). This tests the null hypothesis that the test statistic is equal to 0 (i.e. that there is no co-integration at all). If co-integration had been present, then a VECM model would be run and an impulse response functions obtained. VECM has been used in the addictions field to assess the relationship between alcohol advertising, price and consumption, and to monitor illicit psychostimulants and related health issues $(85,86)$.

Table 1 gives an overview of the key analysis types, what they are used for, required sample sizes, statistical packages that can be used in $\mathrm{R}$ and what assumptions must be met. Tables 2 and 3 give an overview of the stages in GAMM/ARIMA/ARIMAX and VAR/SVAR/VECM, respectively.

Stages in time series analysis with autocorrelations

Eight stages are proposed for GAMM and ARIMA/ARIMAX modelling: 1) assess the presence of autocorrelation, 2) assess the presence of seasonality, 3) determine if the series is stationary (for ARIMAX), 4) identify the number of AR and/or MA terms, 5) identify lags, 6) select the baseline model, 7) run the model and check for additional autocorrelation and 8) check the assumption of normality, significance of autocorrelation terms and whether they are in the bounds of invertibility and stationarity.

Seven stages are proposed for VAR/SVAR/VECM modelling: 1) determine if the series is stationary, 2) identify the number of lags, 3) run the model and assess additional autocorrelation, 4) check the assumption of normality of the residuals, 5) visualise the dynamic relationships, 6) check for causality and 7) check for the presence of co-integrated variables.

\section{PART 4: REPORTING TSA}

There are several useful guides to reporting TSA, including an extension of the 'Strengthening the Reporting of Observational Studies in Epidemiology' (STROBE) guideline $(34,87,88)$. In this part of the paper we extend these to more types of TSA and focus on examples in the field of addiction. A summary of our guidelines is provided in Table 4. 
Statistical analysis plans and related protocols should be registered online prior to data analysis (e.g. using Open Science Framework (http://osf.io/) or AsPredicted (http://AsPredicted.org/) (89). Changes to the analyses, and additional analyses undertaken after seeing any results should be added to that record.

Research reports should include, as a minimum, information on stationarity, seasonality, autocorrelation, lags and criteria for model fit. For interrupted time series designs additional information is required in terms of the intervention time point, number of data points pre- and postintervention and use of a graphical display with the time points clearly defined.

Coefficients are interpreted in a similar way to those from a simple regression model except when the data have been made stationary prior to data analysis. Interpretation also depends on whether a log transformation or equivalent has been performed. As an example, Table 5 provides a set of standard interpretations of coefficients under different log transformation scenarios in the presence of stationary data. For example, when the input and output time series have been log transformed using a natural log transformation and the data made stationary we can interpret the coefficients in terms of elasticity i.e. a change of $1 \%$ from the overall mean value in the input series leads to a $\beta \%$ change from the overall mean in the output series.

Researchers should also consider the use of Bayes Factors to help in the interpretation of null findings. In frequentist statistics, it is not justified to argue that a 'non-significant' finding provides evidence for the null hypothesis. Jeffreys (90) has proposed that we regard a Bayes Factor of less than $1 / 3^{\text {rd }}$ as providing strong evidence that the null hypothesis is more likely than the experimental hypothesis, and a Bayes Factor between $1 / 3^{\text {rd }}$ and 3 as meaning that the data are insensitive. Several software packages are available for the calculation of Bayes Factors including an online calculator (91) and R code (92). Both approaches require the specification of an expected effect size (i.e. a plausible range of predicted values based on previous studies, judgement or clinical significance), the obtained effect size (e.g. mean difference or log odds ratio) and standard error of this parameter. For further details see (93).

\section{DISCUSSION}

Apart from simple trend analyses, there are two main types of TSA: 1) interrupted TSA which are used to assess the impact of interventions, events or policies on a time series and 2) multiple TSA which aim to assess how two or more time series co-vary. Both have several components that need to be considered in the analysis process including the presence of autocorrelation, seasonality and 
lags, and the need for log transformations and differencing to ensure stationarity in the mean and variance.

This paper started by considering regression methods which are appropriate for analyses in the absence of autocorrelation. For interrupted time series designs in the presence of autocorrelation, ARIMA and GAMM are commonly used. Factors to consider when deciding between these two options include the nature of the effect (e.g. step level change or pulse effect), and the use of preaggregated versus individual level data. It is more appropriate to use individual level data when there is reason to believe that the intervention does not have the same uniform effect across all cases. ARIMAX is widely used for multiple TSA as it better accounts for autocorrelation. VAR, SVAR or VECM are increasingly widely used for multiple time series and are required when there may be bidirectional causal associations between variables.

We have not covered the use of time series data for forecasting, nor have we covered methods of validating models. For forecasting, ARIMA/ARIMAX and VAR models are commonly used (41). It should also be noted that other approaches exist for the analysis of time series data that are beyond the scope of this paper (see $(35,87,94)$. These other related types of analysis include the use of simultaneous or structural equation models (SEQ) (83) and ARIMA in conjunction with a Generalised AutoRegressive Conditional Heteroscedasticity (GARCH) models. The latter removes the need for the assumption of constant variance over-time, but optimisation problems are common (95).

Random Forest regression, based on decision trees, is also widely reported in the machine learning literature (96). For single case intervention analysis, the interrupted time series experiment (ITSE) method has been proposed, although it has major limitations (97). Latent growth curve modelling provides another useful method for analysing intervention effects on individual cases (98) and aggregated time series (99). Use of artificial neural networks has also been suggested as a method for TSA which can capture non-linearity and chaotic behaviour (100). Finally, periodograms and spectral analysis can be used to identify complex cycles and seasonality in the data (101).

\section{Funding}

No funders had any involvement in the writing of this report or the decision to submit the paper for publication. EB, JB \& IT salaries are funded by a programme grant from Cancer Research UK (CRUK; C1417/A22962). EB and SM receive support from National Institute for Health Research (NIHR) SPHR2. SPHR is a partnership between the Universities of Sheffield; Bristol; Cambridge; Imperial College London; UCL; The London School for Hygiene and Tropical Medicine; the LiLaC collaboration 
between the Universities of Liverpool and Lancaster and Fuse; The Centre for Translational Research in Public Health, a collaboration between Newcastle, Durham, Northumbria, Sunderland and Teesside Universities. JM has a part-time position as Senior Academic Advisor to the Division of Alcohol, Drugs, Tobacco and Justice Division of Public Health England. The views expressed are those of the authors(s) and not necessarily those of the Department of Health, PHE, or NIHR.
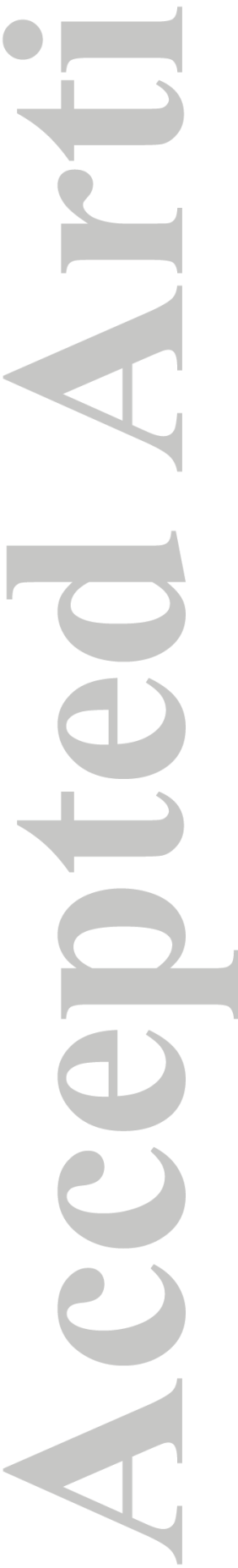

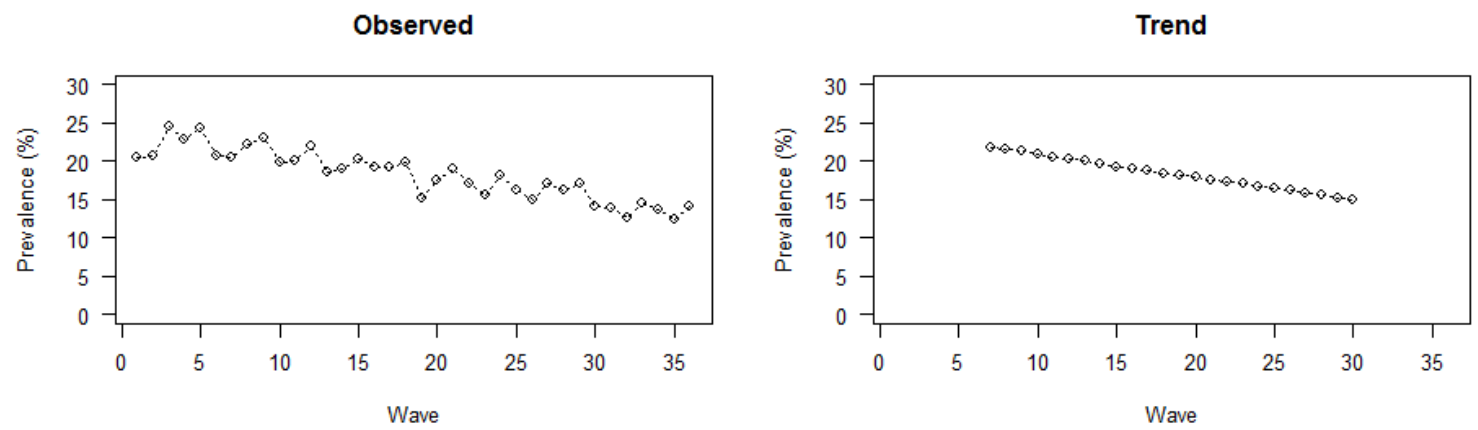

Seasonal
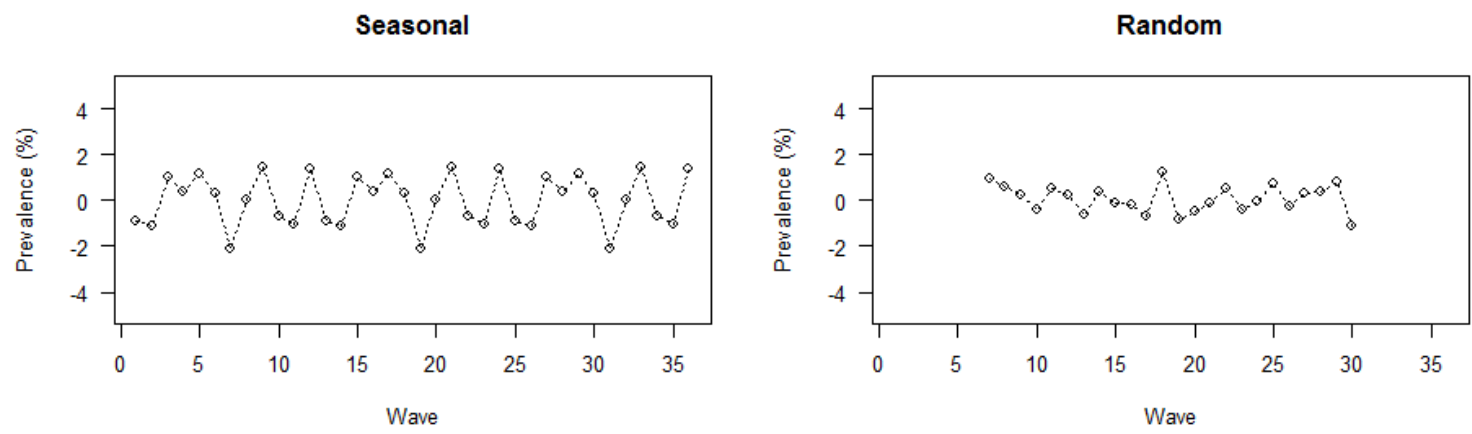

Figure 1: Decomposition of time series data for a hypothetical series of prevalence of excessive alcohol consumption in a population 

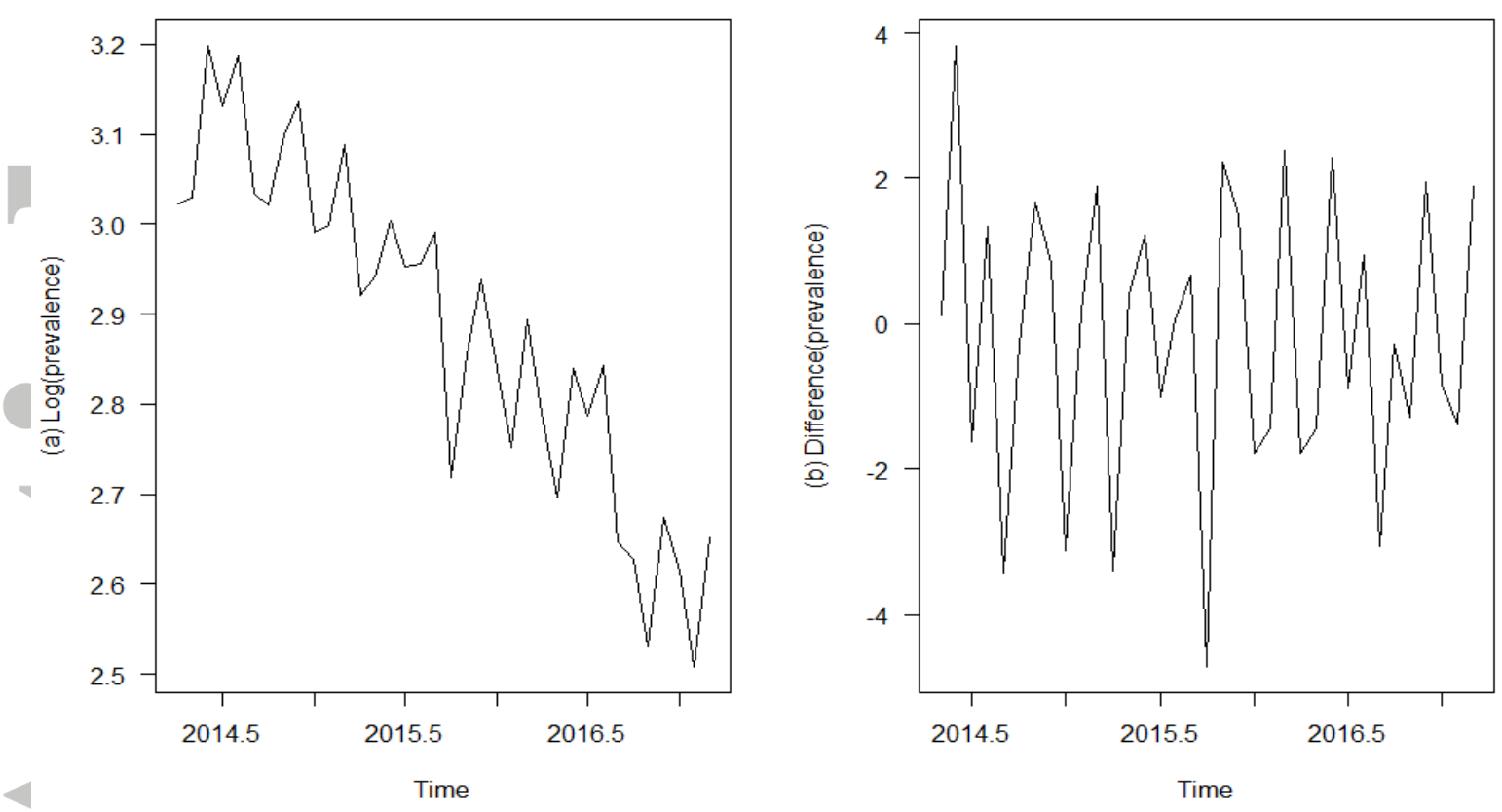

Figure 2: Hypothetical time series data for excessive alcohol consumption after (a) a log transformation and (b) first order differencing to remove non-stationarity
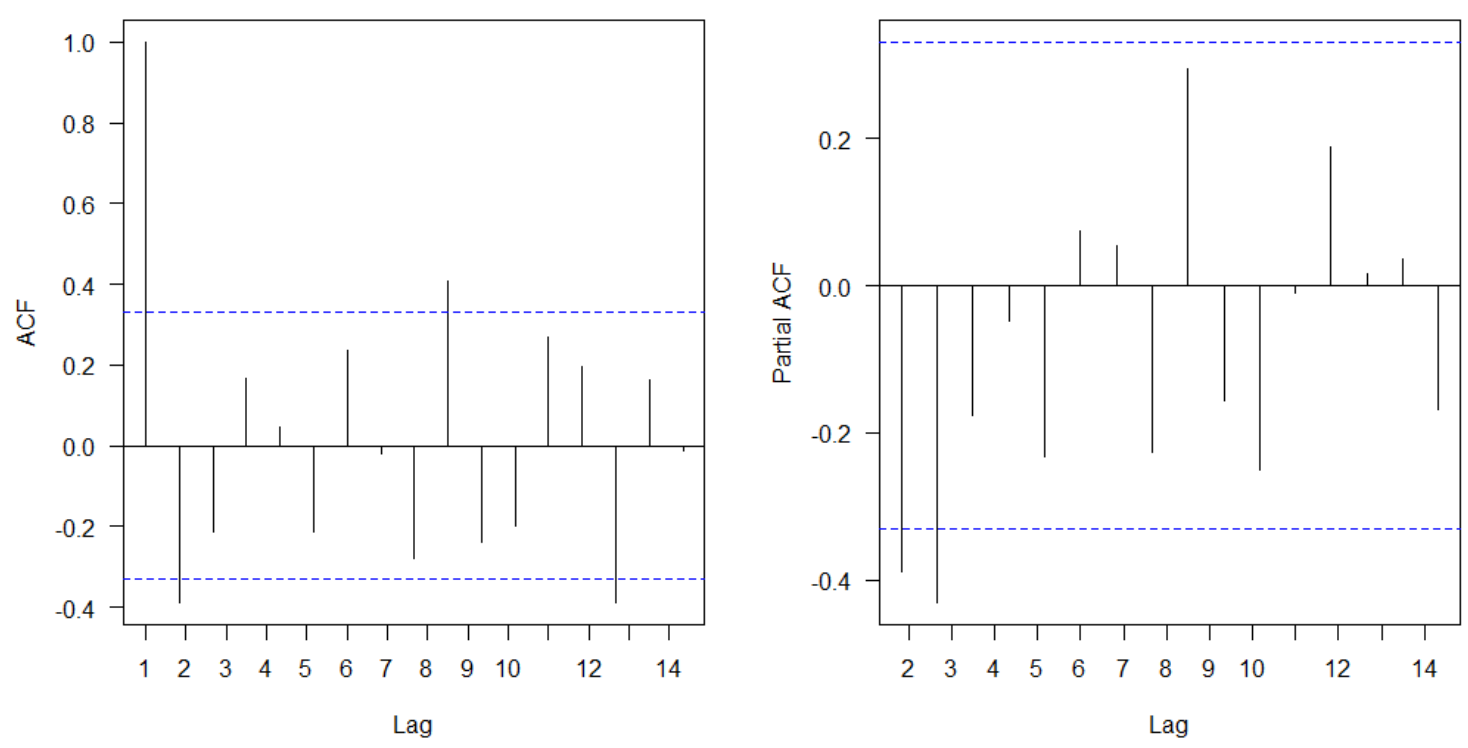

Figure 3: ACF and PACF for excessive alcohol consumption after differencing 
(a)

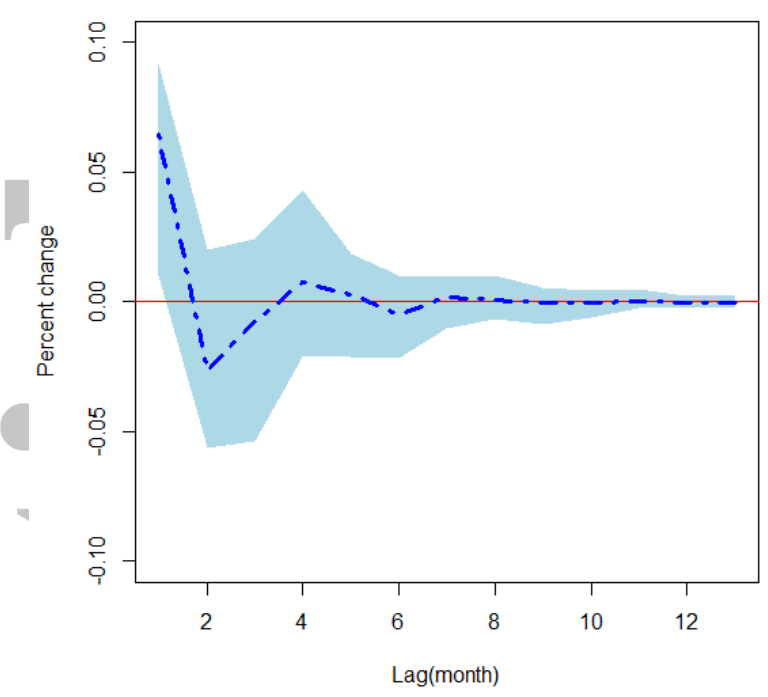

(b)

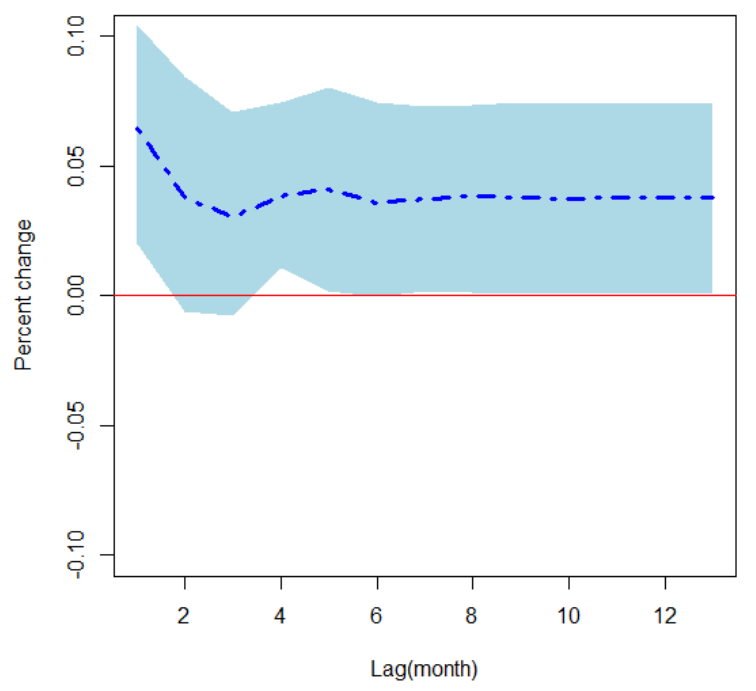

Figure 4: (a) Orthogonalised Impulse Response Function and (b) Cumulative Impulse Response Function for a VAR model of smoking prevalence and high-risk drinking

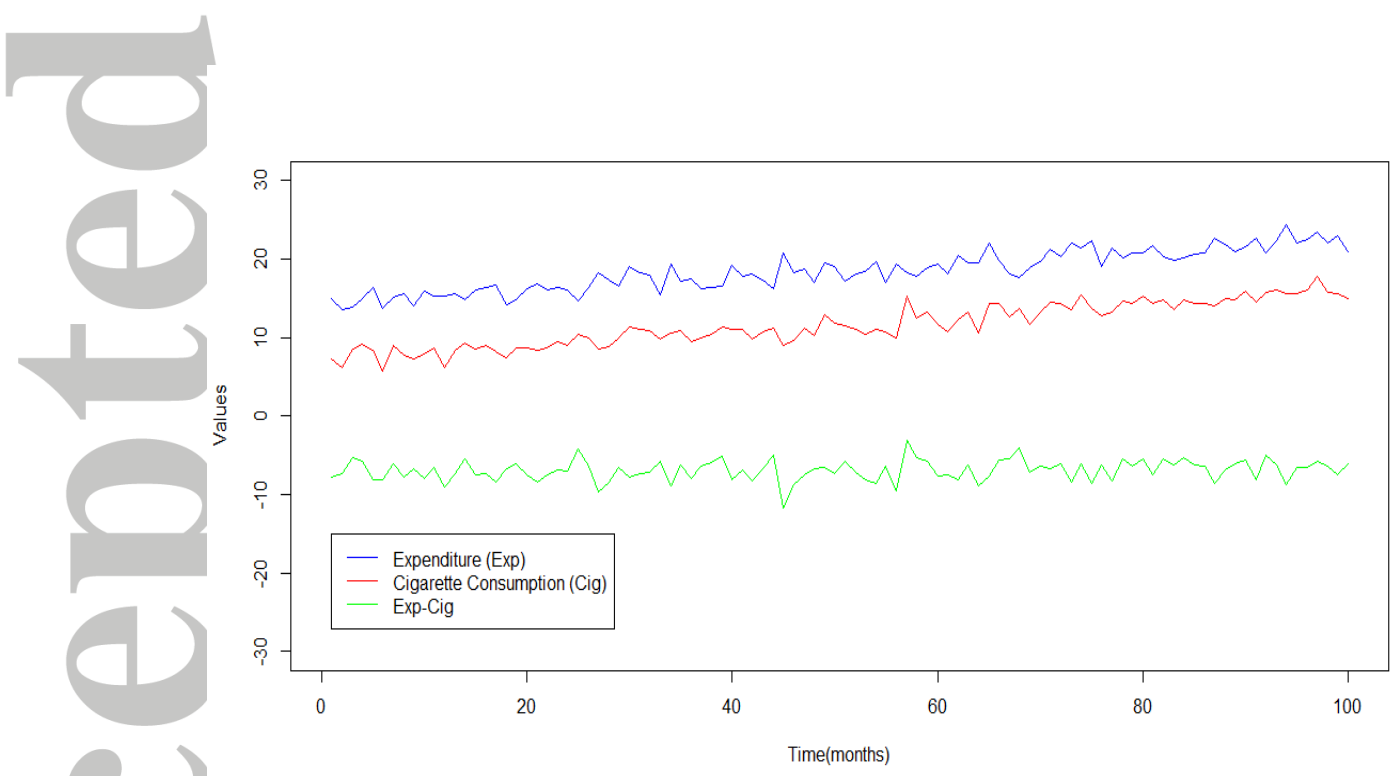

Figure 5: Demonstration of co-integration: graph shows the mean expenditure on cigarettes and cigarette consumption per day as well as the difference between the two 
Table 1: Summary of TSA features

\begin{tabular}{|c|c|c|c|c|c|c|c|c|}
\hline $\begin{array}{l}\text { TSA } \\
\text { model }\end{array}$ & Used for & R packages & $\begin{array}{l}\text { Level of } \\
\text { data } \\
\text { analysis }\end{array}$ & $\begin{array}{l}\text { Variable type } \\
\text { of output } \\
\text { series }\end{array}$ & Autocorrelation & $\begin{array}{l}\text { Seasonality } \\
\text { adjustment }\end{array}$ & Sample size & Assumptions \\
\hline GLMM & $\begin{array}{l}\text { Trend analysis and } \\
\text { interrupted time series } \\
\text { analysis; can also assess } \\
\text { multiple time series if there } \\
\text { are no lag effects } \\
\text { Trend analysis and } \\
\text { interrupted time series } \\
\text { analysis; can also assess } \\
\text { multiple time series if there } \\
\text { are no lag effects }\end{array}$ & $\begin{array}{l}\text { 'glmm'(102) } \\
\text { 'Ime4' (103) } \\
\text { 'nlme'(104) } \\
\text { 'nlme'(104) }\end{array}$ & $\begin{array}{l}\text { Individual } \\
\text { or } \\
\text { aggregated }\end{array}$ & Any & $\begin{array}{l}\text { Can account for MA and AR } \\
\text { autocorrelation } \\
\text { Can account for MA and AR } \\
\text { autocorrelation }\end{array}$ & 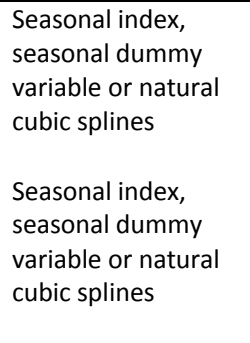 & $\begin{array}{l}\text { Fewer than } 50 \text { data points leads to biased } \\
\text { estimates }(105,106) \text {. If data are at the individual } \\
\text { level sample size should be at least } 100 \\
\text { participants per time point (106). } \\
\text { Fewer than } 50 \text { data points leads to biased } \\
\text { estimates }(105,106) \text {. If data are at the individual } \\
\text { level sample size should be at least } 100 \\
\text { participants each time point (106). }\end{array}$ & $\begin{array}{l}\text { Standard regression assumptions } \\
\text { apply e.g. normally distributed errors } \\
\text { Standard regression assumptions } \\
\text { apply as for GLMM with the Gaussian } \\
\text { distribution. }\end{array}$ \\
\hline GAMM & $\begin{array}{l}\text { Trend analysis and } \\
\text { interrupted time series } \\
\text { analysis; can also assess } \\
\text { multiple time series if there } \\
\text { are no lag effects }\end{array}$ & $\begin{array}{l}\text { 'mgcv' (107) } \\
\text { 'gamm4' } \\
(108)\end{array}$ & $\begin{array}{l}\text { Individual } \\
\text { or } \\
\text { aggregated }\end{array}$ & Any & $\begin{array}{l}\text { Can account for MA and } \\
\text { AR autocorrelation }\end{array}$ & $\begin{array}{l}\text { Seasonal index, } \\
\text { seasonal dummy } \\
\text { variable or natural } \\
\text { smoothing terms }\end{array}$ & $\begin{array}{l}\text { Large sample sizes required as for generalised } \\
\text { linear mixed models, but larger if smoothing } \\
\text { terms are used with multiple knots e.g. } 12 \\
\text { knots are used for } 12 \text { months generally (109). } \\
\text { Sample size at lower level has a smaller impact, } \\
\text { though at least } 100 \text { participants are } \\
\text { recommended (106). }\end{array}$ & $\begin{array}{l}\text { As GAMM are semi-parametric } \\
\text { extensions of GLMs; the only } \\
\text { underlying assumption made is that } \\
\text { the functions are additive and that } \\
\text { the components are smooth. }\end{array}$ \\
\hline ARIMA & $\begin{array}{l}\text { Trend analysis and } \\
\text { interrupted time series } \\
\text { analysis }\end{array}$ & $\begin{array}{l}\text { 'forecast' } \\
(110)\end{array}$ & Aggregated & Continuous & $\begin{array}{l}\text { Can account for both } \\
\text { seasonal and non- } \\
\text { seasonal MA and AR } \\
\text { autocorrelation }\end{array}$ & $\begin{array}{l}\text { Accounted for } \\
\text { through seasonal } \\
\text { differencing and the } \\
\text { use of seasonal MA } \\
\text { and AR terms }\end{array}$ & $\begin{array}{l}\text { Some have recommended at least } 50-100 \\
\text { observations in total }(31,32) \text {, while others have } \\
\text { argued that short-time series data can be used } \\
\text { so long as there are more observation periods } \\
\text { than parameters (33). }\end{array}$ & $\begin{array}{l}\text { Standard parametric assumptions } \\
\text { e.g. linearity, multicollinearity and } \\
\text { heteroscedasticity as well as } \\
\text { stationarity and invertibility. }\end{array}$ \\
\hline ARIMAX & $\begin{array}{l}\text { Multiple time series analysis; } \\
\text { can also add interrupted } \\
\text { time series as covariates }\end{array}$ & 'TSA' (111) & Aggregated & Continuous & $\begin{array}{l}\text { Can account for both } \\
\text { seasonal and non- } \\
\text { seasonal MA and AR } \\
\text { autocorrelation }\end{array}$ & $\begin{array}{l}\text { Accounted for } \\
\text { through seasonal } \\
\text { differencing and the } \\
\text { use of seasonal MA } \\
\text { and AR terms } \\
\end{array}$ & $\begin{array}{l}\text { Some have recommended at least } 50-100 \\
\text { observations in total }(31,32) \text {, while others have } \\
\text { argued that short-time series data can be used } \\
\text { so long as there are more observation periods } \\
\text { than parameters (33). }\end{array}$ & $\begin{array}{l}\text { Same as for ARIMA plus the } \\
\text { assumption of weak exogeneity. }\end{array}$ \\
\hline VAR & $\begin{array}{l}\text { Multiple time series analysis } \\
\text { with bidirectional causation } \\
\text { between input and output } \\
\text { variables }\end{array}$ & 'vars' (112) & Aggregated & Continuous & $\begin{array}{l}\text { Does not include MA } \\
\text { terms, but approximates } \\
\text { any existing MA patterns } \\
\text { with extra AR lags } \\
\end{array}$ & $\begin{array}{l}\text { Seasonal dummy } \\
\text { variables can be } \\
\text { added as exogenous } \\
\text { variables }\end{array}$ & $\begin{array}{l}\text { Similar sample size to ARIMAX models, with a } \\
\text { large number of data points required if a } \\
\text { seasonal dummy variable is included. }\end{array}$ & $\begin{array}{l}\text { VAR and SVAR are not suitable in the } \\
\text { presence of co-integrating } \\
\text { relationships }\end{array}$ \\
\hline VECM & $\begin{array}{l}\text { Multiple time series analysis } \\
\text { with bidirectional causation } \\
\text { between input and output } \\
\text { variables }\end{array}$ & 'tsDyn' (113) & Aggregated & Continuous & $\begin{array}{l}\text { Does not include MA } \\
\text { terms, but approximates } \\
\text { any existing MA patterns } \\
\text { with extra AR lags } \\
\end{array}$ & $\begin{array}{l}\text { Seasonal dummy } \\
\text { variables can be } \\
\text { added as exogenous } \\
\text { variables }\end{array}$ & $\begin{array}{l}\text { Similar sample size to ARIMAX models, with a } \\
\text { large number of data points required if a } \\
\text { seasonal dummy variable is included. }\end{array}$ & $\begin{array}{l}\text { VAR and SVAR are not suitable in the } \\
\text { presence of co-integrating } \\
\text { relationships }\end{array}$ \\
\hline SVAR & Multiple time series analysis & 'vars'(112) & Aggregated & Continuous & Does not include MA & Seasonal dummy & Similar sample size to ARIMAX models, with a & VAR and SVAR are not suitable in the \\
\hline
\end{tabular}

This article is protected by copyright. All rights reserved. 


\begin{tabular}{|l|l|l|l|l|l|l|l|}
\hline $\begin{array}{l}\text { with bidirectional causation } \\
\text { between input and output } \\
\text { variables }\end{array}$ & & $\begin{array}{l}\text { terms, but approximates } \\
\text { any existing MA patterns } \\
\text { with extra AR lags }\end{array}$ & $\begin{array}{l}\text { variables can be } \\
\text { added as exogenous } \\
\text { variables }\end{array}$ & $\begin{array}{l}\text { large number of data points required if a } \\
\text { seasonal dummy variable is included. }\end{array}$ \\
\hline
\end{tabular}

This article is protected by copyright. All rights reserved. 
Table 2: Steps in TSA for GAMM/ARIMA/ARIMAX models

\begin{tabular}{|c|c|c|c|}
\hline Step & Method & Multiple time series & Interrupted time series \\
\hline $\begin{array}{l}\text { Assess the presence of } \\
\text { autocorrelation }\end{array}$ & $\begin{array}{l}\text { Simple lag-1 } \\
\text { autocorrelation can be } \\
\text { detected with the use of } \\
\text { the Durbin Watson } \\
\text { statistic. For more } \\
\text { complex patterns, the } \\
\text { Autocorrelation Function } \\
\text { (ACF) and Partial } \\
\text { Autocorrelation Function } \\
\text { (PACF) should be referred } \\
\text { to. }\end{array}$ & $\begin{array}{l}\text { No autocorrelation } \\
\text { Simple regression } \\
\text { Autocorrelation } \\
\text { ARIMAX }\end{array}$ & $\begin{array}{l}\text { No autocorrelation } \\
\text { Simple regression } \\
\text { Autocorrelation } \\
\text { GAMM if limited number of data points, only } \\
\text { interested in step level effects and want to assess } \\
\text { moderation of individual level variables. } \\
\text { ARIMA if long time series and interested in } \\
\text { differing patterns of effects (e.g. pulse, step and } \\
\text { delayed effects). }\end{array}$ \\
\hline $\begin{array}{l}\text { Assess the presence of } \\
\text { seasonality }\end{array}$ & $\begin{array}{l}\text { Plot of the raw time series } \\
\text { data and use the ACF and } \\
\text { PACF. Look for significant } \\
\text { lags at seasonal points } \\
\text { (e.g. lag } 4 \text { and } 8 \text { for } \\
\text { quarterly data) in the } \\
\text { later, and cyclical patterns } \\
\text { in the former. }\end{array}$ & $\begin{array}{l}\text { No seasonal effects } \\
\text { Simple regression if no autocorrelation. } \\
A R I M A X \text { if autocorrelation is present } \\
\text { Seasonal effects } \\
\text { Simple regression with a cubic spline if } \\
\text { no autocorrelation (STOP). } \\
\text { ARIMAX if autocorrelation is also } \\
\text { present. }\end{array}$ & $\begin{array}{l}\text { No seasonal effects } \\
\text { Simple regression if no autocorrelation. } \\
\text { GAMM if autocorrelation is present and you have } \\
\text { limited number of data points, only interested in } \\
\text { step level effects and want to assess moderation } \\
\text { of individual level variables. } \\
\text { ARIMA if autocorrelation is present and you have } \\
\text { a long-time series and interested in differing } \\
\text { patterns of effects (e.g. pulse, step and delayed } \\
\text { effects). } \\
\text { Seasonal effects } \\
\text { Simple regression with a cubic spline if no } \\
\text { autocorrelation. } \\
\text { GAMM if autocorrelation is present and you have } \\
\text { limited number of data points, only interested in } \\
\text { step level effects and want to assess moderation } \\
\text { of individual level variables. } \\
\text { ARIMA if autocorrelation is present and you have } \\
\text { a long-time series and interested in differing } \\
\text { patterns of effects (e.g. pulse, step and delayed } \\
\text { effects). }\end{array}$ \\
\hline $\begin{array}{l}\text { Determine if the se } \\
\text { is stationary }\end{array}$ & $\begin{array}{l}\text { If autocorrelation is } \\
\text { present, check if the } \\
\text { series is stationary. This } \\
\text { can be done by using unit } \\
\text { root tests and visually } \\
\text { inspecting the series } \\
\text { graphically }\end{array}$ & $\begin{array}{l}\text { If the variance is not constant over } \\
\text { time, consider a natural logarithmic } \\
\text { transformation. If the mean is not } \\
\text { constant over time, difference the data. } \\
\text { Consider both seasonal and non- } \\
\text { seasonal differencing. }\end{array}$ & $\begin{array}{l}\text { If the variance is not constant over time, consider } \\
\text { a natural logarithmic transformation. If the mean } \\
\text { is not constant over time, difference the data. } \\
\text { Consider both seasonal and non-seasonal } \\
\text { differencing. }\end{array}$ \\
\hline $\begin{array}{l}\text { Identify the numbe } \\
\text { AR and MA terms }\end{array}$ & $\begin{array}{l}\text { The ACF and PACF can be } \\
\text { used to determine the } \\
\text { number of } \\
\text { autocorrelation terms } \\
\text { required. }\end{array}$ & $\begin{array}{l}\text { A steadily decaying ACF and a PACF that } \\
\text { drops after } p \text { lags would be consistent } \\
\text { with an AR term. In contrast, an MA } \\
\text { term would be consistent with a ACF } \\
\text { that drops off after q lags and a gradual } \\
\text { decay in the PACF. }\end{array}$ & $\begin{array}{l}\text { A steadily decaying ACF and a PACF that drops } \\
\text { after } p \text { lags would be consistent with an AR term. } \\
\text { In contrast, an MA term would be consistent with } \\
\text { a ACF that drops off after q lags and a gradual } \\
\text { decay in the PACF. }\end{array}$ \\
\hline Identify any & $\begin{array}{l}\text { This can be done by } \\
\text { comparing models with } \\
\text { different lag effects using } \\
\text { the AIC. For multiple time } \\
\text { series analysis, the CCF } \\
\text { can be used. }\end{array}$ & $\begin{array}{l}\text { If there is evidence of lag effect include } \\
\text { this in the ARIMAX model by specifying } \\
\text { a transfer function. }\end{array}$ & $\begin{array}{l}\text { If there are no lag effects continue with the } \\
\text { chosen analysis, if there is evidence of a lag } \\
\text { effect consider using ARIMA models. }\end{array}$ \\
\hline $\begin{array}{l}\text { Select the base } \\
\text { model }\end{array}$ & $\begin{array}{l}\text { Run the baseline model } \\
\text { with the input series (and } \\
\text { covariates) included and } \\
\text { compare with other } \\
\text { models using the AIC }\end{array}$ & $\begin{array}{l}\text { If other models provide a better fit, } \\
\text { consider these over the baseline model. }\end{array}$ & $\begin{array}{l}\text { If other models provide a better fit, consider } \\
\text { these over the baseline model. }\end{array}$ \\
\hline $\begin{array}{l}\text { Run the model and } \\
\text { check for additional } \\
\text { autocorrelation }\end{array}$ & $\begin{array}{l}\text { Examine the model } \\
\text { residuals and check the } \\
\text { Ljung-Box test }\end{array}$ & $\begin{array}{l}\text { If the residuals form a random pattern } \\
\text { and the Ljung-Box test is non-significant } \\
\text { do not change model. If a pattern } \\
\text { remains and there is evidence of } \\
\text { further autocorrelation consider adding } \\
\text { additional seasonal or non-seasonal AR } \\
\text { and MA terms. }\end{array}$ & $\begin{array}{l}\text { If the residuals form a random pattern and the } \\
\text { Ljung-Box test is non-significant do not change } \\
\text { model. If a pattern remains and there is evidence } \\
\text { of further autocorrelation consider adding } \\
\text { additional seasonal or non-seasonal AR and MA } \\
\text { terms. The latter of which can only be added to } \\
\text { ARIMA models. }\end{array}$ \\
\hline $\begin{array}{l}\text { Check the assumption } \\
\text { of normality, } \\
\text { significance of } \\
\text { autocorrelation terms }\end{array}$ & $\begin{array}{l}\text { These can be checked } \\
\text { with q-q plots and } \\
\text { assessing the size and } \\
\text { significance of }\end{array}$ & $\begin{array}{l}\text { If MA and AR terms do not contribute } \\
\text { significantly or violate the assumption } \\
\text { of bounds of invertibility and } \\
\text { stationarity remove from the analysis. }\end{array}$ & $\begin{array}{l}\text { If MA and AR terms do not contribute } \\
\text { significantly or violate the assumption of bounds } \\
\text { of invertibility and stationarity remove from the } \\
\text { analysis. }\end{array}$ \\
\hline
\end{tabular}



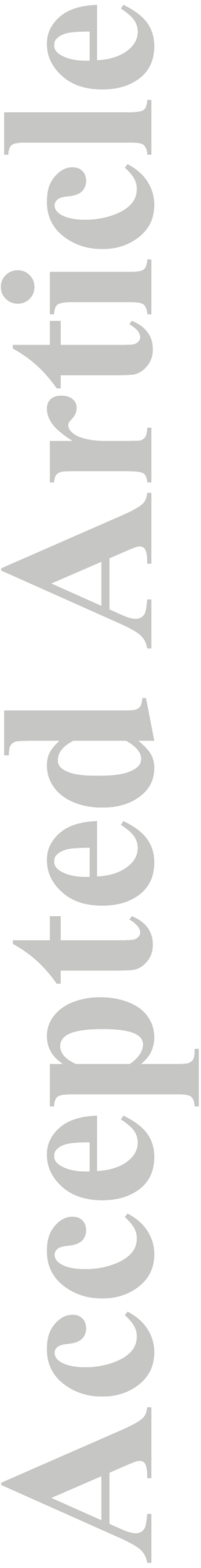
Table 3: Steps in a VAR/SVAR/VECM

\begin{tabular}{l|l}
\hline Step & Method \\
\hline \hline Determine if the series is stationary & $\begin{array}{l}\text { If autocorrelation is present, check if the series is } \\
\text { stationary. This can be done by using unit root } \\
\text { tests and visually inspecting the series graphically }\end{array}$ \\
\hline Identify the number of lags & $\begin{array}{l}\text { This can be done by comparing models with } \\
\text { different lag effects using the AIC. }\end{array}$ \\
\hline $\begin{array}{l}\text { Run the model and assess additional } \\
\text { autocorrelation }\end{array}$ & $\begin{array}{l}\text { Autocorrelation among the residuals assessed } \\
\text { using a Portmanteau test }\end{array}$ \\
\hline $\begin{array}{l}\text { Check the assumption of normality of } \\
\text { residuals }\end{array}$ & $\begin{array}{l}\text { This can be done using the Jarque-Bera normality } \\
\text { tests for multivariate series }\end{array}$ \\
\hline $\begin{array}{l}\text { Visualise the equations } \\
\text { Check for causality }\end{array}$ & $\begin{array}{l}\text { Calculate the impulse response function and } \\
\text { cumulative impulse response function }\end{array}$ \\
\hline $\begin{array}{l}\text { Check for the presence of co-integrated } \\
\text { variables }\end{array}$ & $\begin{array}{l}\text { Run the Granger causality test and instant } \\
\text { causality test }\end{array}$ \\
\hline
\end{tabular}

This article is protected by copyright. All rights reserved. 
Table 4: Guidelines for the reporting of TSA

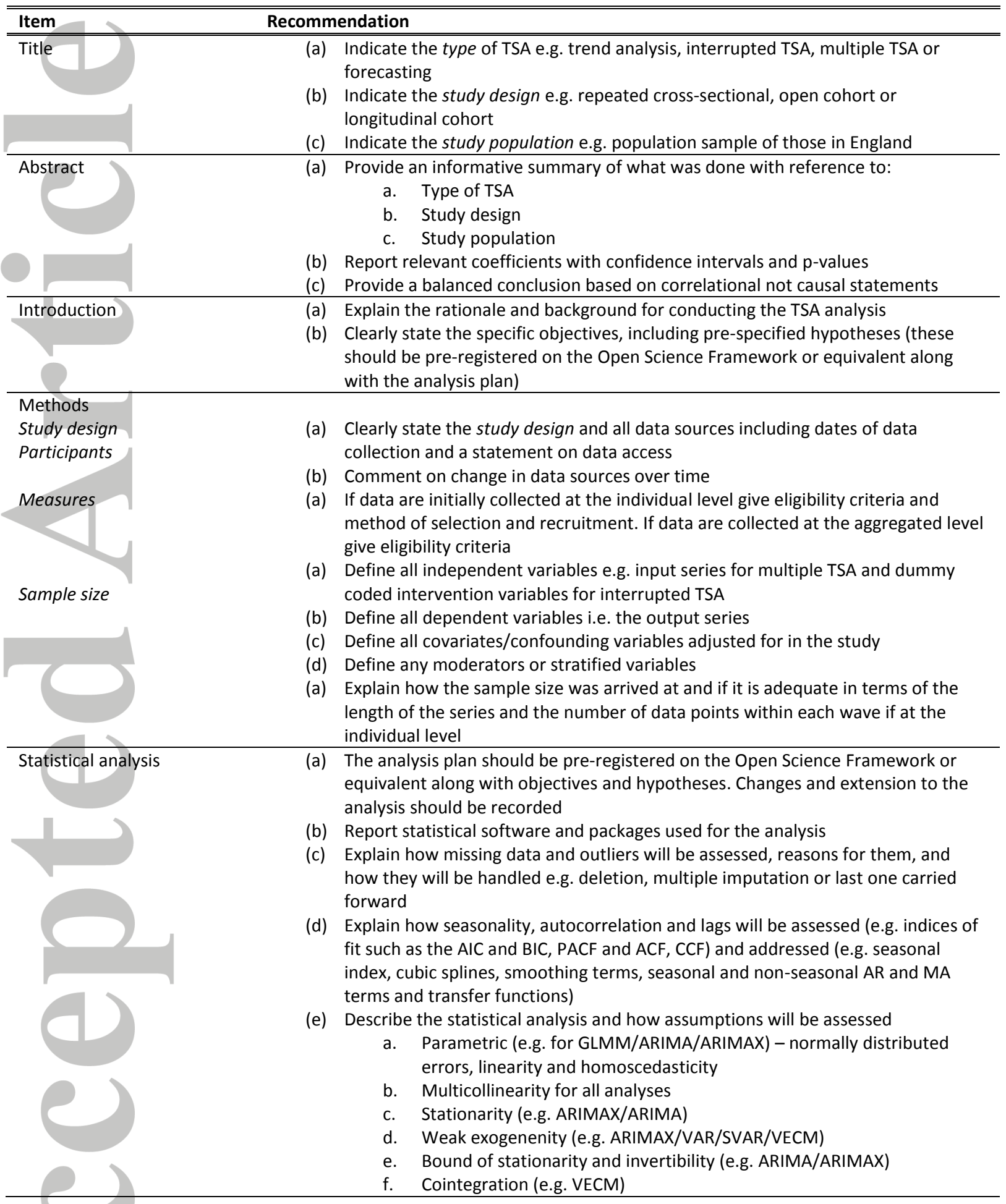


Table 4: Guidelines for the reporting of TSA (continued)

\begin{tabular}{|c|c|c|}
\hline Item & Recomn & endation \\
\hline Statistical analysis & $\begin{array}{l}\text { (c) } \\
\text { (d) } \\
\text { (e) }\end{array}$ & $\begin{array}{l}\text { Describe how violations of the assumptions will be handled } \\
\text { a. Transformations e.g. log transformation for stationarity and parametric } \\
\text { assumptions } \\
\text { b. Differencing for stationarity } \\
\text { c. Selection methods for multicollinearity } \\
\text { d. Other analysis options } \\
(64,93) \text { Consider the calculation of Bayes Factors to aid interpretation of null } \\
\text { findings (64, 93) } \\
\text { State all underlying assumptions } \\
\text { State any unplanned sensitivity analyses and the reasons for them } \\
\text { Explain how any continuous variables were categorised for the analysis and } \\
\text { comment on changes in variable coding over time } \\
\text { Give guidelines on the interpetation of coefficients taking into account } \\
\text { transformations of the data (see Table } 5 \text { for examples) }\end{array}$ \\
\hline $\begin{array}{l}\text { Results } \\
\text { Participants } \\
\text { Descriptive s }\end{array}$ & $\begin{array}{l}\text { (b) } \\
\text { (a) } \\
\text { (b) }\end{array}$ & $\begin{array}{l}\text { If data are available at the individual level report the total number taking part in } \\
\text { the study (and the average number recruited at each stage if cross-sectional). For } \\
\text { cohort studies give details on those lost to follow up. } \\
\text { If data are available at the individual level report characteristics e.g. } \\
\text { demographic. If data are available at the aggregated level report the start, end } \\
\text { and average values of each series in the analysis } \\
\text { Provide graphical figures of the aggregated data over time } \\
\text { Give adjusted and unadjusted estimates and their precision e.g. 95\% confidence } \\
\text { interval and, if applicable, Bayes Factors } \\
\text { Specify the final model e.g. AR and MA terms, order of differencing and presence } \\
\text { of lags } \\
\text { Report any analyses e.g. moderation, subgroup and unplanned sensitivity } \\
\text { Present results using a graphical display with intervention time point(s) clearly } \\
\text { defined for interrupted time series }\end{array}$ \\
\hline $\begin{array}{l}\text { Discussion } \\
\text { Key results } \\
\text { Limitations } \\
\text { Interpretation } \\
\text { Implications/future research }\end{array}$ & $\begin{array}{l}\text { (a) } \\
\text { (a) } \\
\text { (a) } \\
\text { (a) }\end{array}$ & $\begin{array}{l}\text { Summaries the main findings with reference to the study objectives and aims } \\
\text { Discuss all limitations of the study with a focus on possible bias and imprecision } \\
\text { Give a cautious overall interpretation of results relating them to previous studies } \\
\text { Discuss the possible implications of the findings in relation to policy, clinical } \\
\text { objectives etc } \\
\text { Consider avenues for future research }\end{array}$ \\
\hline $\begin{array}{l}\text { Other information } \\
\text { Funding } \\
\text { Ethical approval } \\
\text { Conflicts of interest }\end{array}$ & $\begin{array}{l}\text { (a) } \\
\text { (a) } \\
\text { (a) }\end{array}$ & $\begin{array}{l}\text { Gives sources of funding for the study } \\
\text { Explain if ethical approval was sought and how } \\
\text { Clearly state any conflicts of interest in relation to the paper }\end{array}$ \\
\hline
\end{tabular}


Table 5: Interpretation of coefficients for predictors in GAMM/ARIMA/ARIMAX/VAR models with stationary data

\begin{tabular}{|c|c|c|}
\hline Predictor variable & Dependent variable & Interpretation \\
\hline Binary (dummy) & Continuous & $\begin{array}{l}\text { The introduction of } X \text { resulted in a } \beta \text { units change in the } \\
\text { average of } Y\end{array}$ \\
\hline Continuo & Continuous & $\begin{array}{l}\text { For every one-unit change in the average of } X \text {, the } \\
\text { average of } Y \text { changes by } \beta \text { units }\end{array}$ \\
\hline ned continuous & Continuous & $\begin{array}{l}\text { A one percent change in the average of } X \text { leads to } \\
\beta \times \ln \left(\frac{101}{100}\right)[\sim \beta / 100] \text { change in the average value of } Y\end{array}$ \\
\hline Binary (du & Log transformed continuous & $\begin{array}{l}\text { The introduction of } \mathrm{X} \text { resulted in a }\left(e^{\beta}-1\right) \times \\
100[\sim \beta \text { 100] percentage change in the average } \\
\text { value of } Y\end{array}$ \\
\hline Continuous & Log transformed continuous & $\begin{array}{l}\text { A one percent change in the average of } X \text { leads to } \\
\left(e^{\beta}-1\right) \times 100[\sim \beta \times 100] \text { percentage change in the } \\
\text { average value of } Y\end{array}$ \\
\hline Log transformed continuous & Log transformed continuous & $\begin{array}{l}\text { A one percent change in the average of } X \text { leads to a } \\
\left(1.01^{\beta}-1\right) \times 100[\sim \beta] \text { percentage change in the } \\
\text { average value of } Y\end{array}$ \\
\hline
\end{tabular}

Note: for ARIMA/ARIMAX models which are stationary i.e. have a constant mean and variance over time, interpretation is in terms of the series mean e.g. for a log-log model a $1 \%$ change in the mean of series y leads to a $\beta \%$ change in the mean of series of $\mathrm{X}$.

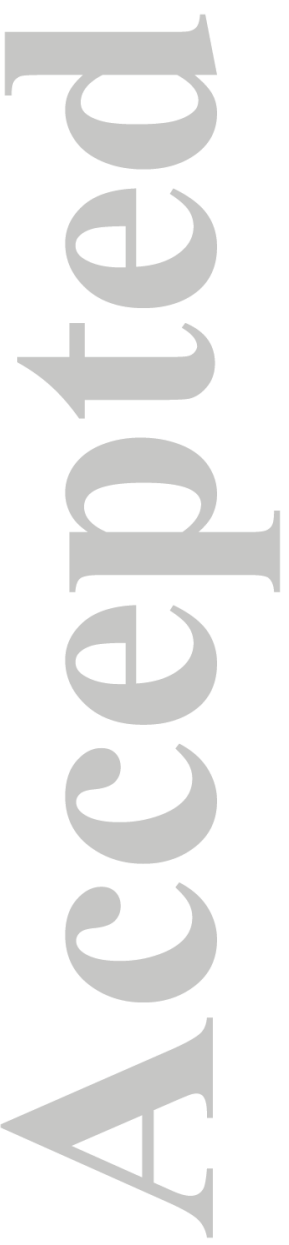

This article is protected by copyright. All rights reserved. 


\section{Appendix A: Glossary}

Aggregated data: Groups of observations are replaced with summary measures.

ARIMA (Autoregressive Integrated Moving Average): a form of regression analysis that seeks to predict future trends whilst taking into account underlying trends, seasonality and autocorrelation. Can be extended to assess the effect of policies or interventions in an interrupted time series design.

ARIMAX (Autoregressive Integrated Moving Average with Exogeneous Input): a form of regression analysis which seeks to assess how two time series covary whilst taking into account underlying trends, seasonality and autocorrelation.

Autocorrelation: Estimates or regression residuals at one time point are correlated with the estimates or residuals at a subsequent time point.

Co-integrating relationship: Two variables share a common stochastic trend in such a way that a linear combination of the variables is stationary.

Differencing: A means by which to make a time series stationary by transforming the series into on made up of the difference between values at time $t$ and values at time $t+n$.

GAM (Generalised Additive Model): Is a generalized linear model which uses an additive modelling technique where the impact of the predictive variables is captured through smooth functions.

GLS (Generalised Least Squares): A statistical technique that allows one to perform linear regression when there is a certain degree of autocorrelation between the residuals.

GLMM (Generalised Linear Mixed Model): An extension to GLM (see below) which contains random effects to account for clustering.

GLM (Generalised Linear Model): A flexible generalization of linear regression that allows for response variables that have error distributions other than a normal distribution.

Parametric test: Makes assumptions about the parameters of the population distribution(s) from which one's data are taken. Non-parametric tests are often referred to as 'distribution-free' tests.

Polynomial terms: Relationships between the independent variable and the dependent variable is modelled as an $n^{\text {th }}$ degree polynomial e.g. quadratic $\left({ }^{\wedge} 2\right)$ and cubic $\left({ }^{\wedge} 3\right)$.

Smoothing spline: Provide a flexible way of representing the relationship between two variables involving fitting of piecewise polynomial terms with breakpoints or changes in the strength and direction of the association.

Stationary: A stationary time series is one whose properties do not depend on the time at which the series is observed. So, a time series with trends or with seasonality cannot be stationary as they will affect the value of the time series at different times. In general, a stationary time series will have no predictable patterns in the long-term.

This article is protected by copyright. All rights reserved. 
SVAR (Structural Vector Autoregressive Model): An extension of VAR (see below) that helps to model the temporal relationships between series by placing restrictions so that relationships can be specified in a unidirectional manner.

VAR (Vector Autoregression): A model that allows specification of bi-directional causal associations between two time series.

Vector Error Correction Model (VECM): An extension of SVAR and VAR which is used in the presence of co-integrating relationships.

Pre-whitening: A procedure that converts an input series into one with a mean of zero and no autocorrelation and applies the same transformation to an output series.

Weak exogeneity: An assumption of ARIMAX models which specifies that there is no reverse causal pathway with the output series having an effect on any of the input variables.

White noise: A white noise series has a mean of zero and no autocorrelation.

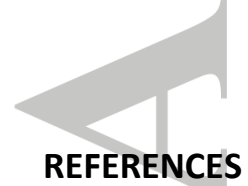

1. Kothari SP, Shanken J. Book-to-market, dividend yield, and expected market returns: A timeseries analysis. Journal of Financial Economics. 1997;44(2):169-203.

$2 . \quad$ Montgomery DC, Johnson LA, Gardiner JS. Forecasting and time series analysis: McGraw-Hill Companies; 1990.

3. Montgomery $\mathrm{DC}$, Jennings $\mathrm{CL}$, Kulahci $\mathrm{M}$. Introduction to time series analysis and forecasting: John Wiley \& Sons; 2015.

4. Cryer JD, Chan K-S. Time series analysis - with applications in R. London: Springer-Verlag New York; 2008.

5. Dierker L, Stolar M, Lloyd-Richardson E, Tiffany S, Flay B, Collins L, et al. Tobacco, alcohol, and marijuana use among first-year U.S. college students: a time series analysis. Subst Use Misuse. 2008;43(5):680-99.

6. Beard E, Brown J, McNeill A, Michie S, West R. Has growth in electronic cigarette use by smokers been responsible for the decline in use of licensed nicotine products? Findings from repeated cross-sectional surveys. Thorax. 2015:thoraxjnl-2015-206801.

7. Langley TE, McNeill A, Lewis S, Szatkowski L, Quinn C. The impact of media campaigns on smoking cessation activity: a structural vector autoregression analysis. Addiction. 2012;107(11):2043-50.

8. Brunt TM, van Laar M, Niesink RJ, van den Brink W. The relationship of quality and price of the psychostimulants cocaine and amphetamine with health care outcomes. Drug and alcohol dependence. 2010;111(1-2):21-9.

9. Holder HD, Wagenaar AC. Mandated server training and reduced alcohol-involved traffic crashes: a time series analysis of the Oregon experience. Accident Analysis \& Prevention. 1994;26(1):89-97.

10. Kuipers MAG, Beard E, Hitchman SC, Brown J, Stronks K, Kunst AE, et al. Impact on smoking of England's 2012 partial tobacco point of sale display ban: a repeated cross-sectional national study. Tobacco Control. 2016.

11. Langley T, Szatkowski L, Lewis S, McNeill A, Gilmore AB, Salway R, et al. The freeze on mass media campaigns in England: a natural experiment of the impact of tobacco control campaigns on quitting behaviour. Addiction. 2014;109(6):995-1002. 
12. Langley TE, Huang Y, McNeill A, Coleman T, Szatkowski L, Lewis S. Prescribing of smoking cessation medication in England since the introduction of varenicline. Addiction. 2011;106(7):131924.

13. Humphreys DK, Eisner MP, Wiebe DJ. Evaluating the Impact of Flexible Alcohol Trading Hours on Violence: An Interrupted Time Series Analysis. PLoS ONE. 2013;8(2):e55581.

14. Robinson M, Geue C, Lewsey J, Mackay D, McCartney G, Curnock E, et al. Evaluating the impact of the alcohol act on off-trade alcohol sales: a natural experiment in Scotland. Addiction (Abingdon, England). 2014;109(12):2035-43.

15. Slováčková T, Birčiaková N, Stávková J. Forecasting Alcohol Consumption in the Czech Republic. Procedia - Social and Behavioral Sciences. 2016;220:472-80.

16. Wang $\mathrm{H}$, Preston $\mathrm{SH}$. Forecasting United States mortality using cohort smoking histories. Proceedings of the National Academy of Sciences. 2009;106(2):393-8.

17. Hasse B, Tarr PE, Marques-Vidal P, Waeber G, Preisig M, Mooser V, et al. Strong Impact of Smoking on Multimorbidity and Cardiovascular Risk Among Human Immunodeficiency Virus-Infected Individuals in Comparison With the General Population. Open Forum Infectious Diseases. 2015;2(3):ofv108.

18. Collins GS, Altman DG. An independent and external validation of QRISK2 cardiovascular disease risk score: a prospective open cohort study. BMJ. 2010;340.

19. Marston L, Carpenter JR, Walters KR, Morris RW, Nazareth I, White IR, et al. Smoker, exsmoker or non-smoker? The validity of routinely recorded smoking status in UK primary care: a cross-sectional study. BMJ Open. 2014;4(4).

20. Vincent KB, Kasperski SJ, Caldeira KM, Garnier-Dykstra LM, Pinchevsky GM, O'Grady KE, et al. Maintaining Superior Follow-Up Rates in a Longitudinal Study: Experiences from the College Life Study. International journal of multiple research approaches. 2012;6(1):4406.

21. Kumar S, Nilsen WJ, Abernethy A, Atienza A, Patrick K, Pavel M, et al. Mobile health technology evaluation: the mHealth evidence workshop. American journal of preventive medicine. 2013;45(2):228-36.

22. Shusterman V, Goldberg A, London B. Upsurge in T-wave alternans and nonalternating repolarization instability precedes spontaneous initiation of ventricular tachyarrhythmias in humans. Circulation. 2006;113(25):2880-7.

23. Hedeker D, Demirtas H, Mermelstein RJ. A mixed ordinal location scale model for analysis of Ecological Momentary Assessment (EMA) data. Statistics and its Interface. 2009;2(4):391.

24. Vieira R, McDonald S, Araújo-Soares V, Sniehotta FF, Henderson R. Dynamic modelling of $n-$ of-1 data: powerful and flexible data analytics applied to individualised studies. Health Psychology Review. 2017;11(3):222-34.

25. Beard E, Brown J, Michie S, West R. Using time-series analysis to examine the effects of adding or removing components of digital behavioural interventions and associations between outcomes and patterns of usage. Frontiers in Public Health.

26. Zhang F, Wagner AK, Ross-Degnan D. Simulation-based power calculation for designing interrupted time series analyses of health policy interventions. Journal of clinical epidemiology. 2011;64(11):1252-61.

27. Erdfelder E, Faul F, Buchner A. GPOWER: A general power analysis program. Behavior research methods, instruments, \& computers. 1996;28(1):1-11.

28. Faul F, Erdfelder E, Buchner A, Lang A-G. Statistical power analyses using G* Power 3.1: Tests for correlation and regression analyses. Behavior research methods. 2009;41(4):1149-60.

29. McLeod Al, Vingilis ER. Power Computations for Intervention Analysis. Technometrics : a journal of statistics for the physical, chemical, and engineering sciences. 2005;47(2):174-81.

30. McLeod Al, Vingilis ER. Power Computations in Time Series Analyses for Traffic Safety Interventions. Accident; analysis and prevention. 2008;40(3):1244-8.

31. Yaffee R. An Introduction to Forecasting Time Series with Stata. Taylor \& Francis; 2012. 
32. EPOC. Including Interrupted Time Series (ITS) designs in EPOC review: the Cochrane effective practice and organisation of care group. 1998.

33. Hyndman RJ, Kostenko AV. Minimum sample size requirements for seasonal forecasting models. Foresight. 2007;6(Spring):12-5.

34. Wagner AK, Soumerai SB, Zhang F, Ross-Degnan D. Segmented regression analysis of interrupted time series studies in medication use research. Journal of clinical pharmacy and therapeutics. 2002;27(4):299-309.

35. Box GE, Jenkins GM, Reinsel GC, Ljung GM. Time series analysis: forecasting and control: John Wiley \& Sons; 2015.

36. Hyndman RJ, Athanasopoulos G. Forecasting: principles and practice: OTexts; 2014.

37. Anderson OD. Time series analysis and forecasting: the Box-Jenkins approach: Butterworths London; 1976.

38. Cowpertwait PS, Metcalfe AV. Introductory time series with R: Springer Science \& Business Media; 2009.

39. Fuller WA. Introduction to statistical time series: John Wiley \& Sons; 2009.

40. Phillips PC, Perron P. Testing for a unit root in time series regression. Biometrika. 1988:33546.

41. McCleary R, Hay RA, Meidinger EE, McDowall D. Applied time series analysis for the social sciences: Sage Publications Beverly Hills, CA; 1980.

42. Lütkepohl H, Xu F. The role of the log transformation in forecasting economic variables. Empirical Economics. 2012;42(3):619-38.

43. Box GE, Jenkins GM, Reinsel GC. Time series analysis: forecasting and control: John Wiley \& Sons; 2011.

44. Beard E, West R, Michie S, Brown J. Association between smoking and alcohol-related behaviours: A time-series analysis of population trends in England. Addiction.n/a-n/a.

45. Schünemann H, Hill S, Guyatt G, AkI EA, Ahmed F. The GRADE approach and Bradford Hill's criteria for causation. Journal of Epidemiology \& Community Health. 2010:jech. 2010.119933.

46. Chernick MR, Downing DJ, Pike DH. Detecting outliers in time series data. Journal of the American Statistical Association. 1982;77(380):743-7.

47. Chen C, Liu L-M. Joint estimation of model parameters and outlier effects in time series. Journal of the American Statistical Association. 1993;88(421):284-97.

48. López-de-Lacalle J. R Package tsoutliers. 2017.

49. Jesús Sánchez M, Peña D. The identification of multiple outliers in ARIMA models. Communications in Statistics-Theory and Methods. 2003;32(6):1265-87.

50. Beard E, West R, Michie S, Brown J. Association between smoking and alcohol-related behaviours: a time-series analysis of population trends in England. Addiction. 2017;112(10):1832-41.

51. Velicer WF, Colby SM. A comparison of missing-data procedures for ARIMA time-series analysis. Educational and Psychological Measurement. 2005;65(4):596-615.

52. Rubin DB. Multiple imputation for nonresponse in surveys: John Wiley \& Sons; 2004.

53. Honaker J, King G, Blackwell M. Amelia II: A program for missing data. Journal of Statistical Software. 2011;45(7):1-47.

54. Buuren Sv, Groothuis-Oudshoorn K. mice: Multivariate imputation by chained equations in R. Journal of statistical software. 2010:1-68.

55. Templ M, Alfons A, Kowarik A, Prantner B. VIM: visualization and imputation of missing values. $R$ package version. 2011;2(3).

56. Kihoro Y, Athiany J, Kibunja K. Imputation of incomplete non-stationary seasonal time series. Math Theory Model. 2013;3:142154.

57. Moritz S, Bartz-Beielstein T. imputeTS: time series missing value imputation in R. The $R$ Journal. 2017;9(1):207-18.

58. Bloomfield P. Fourier analysis of time series: an introduction: John Wiley \& Sons; 2004. 
59. Sims CA. Seasonality in regression. Journal of the American Statistical Association. 1974;69(347):618-26.

60. Perrakis K, Gryparis A, Schwartz J, Le Tertre A, Katsouyanni K, Forastiere F, et al. Controlling for seasonal patterns and time varying confounders in time-series epidemiological models: a simulation study. Stat Med. 2014;33(28):4904-18.

61. Lemon $D$, Partridge R. Is weather related to the number of assaults seen at emergency departments? Injury. 2017;48(11):2438-42.

62. Park RE, Mitchell BM. Estimating the autocorrelated error model with trended data. Journal of Econometrics. 1980;13(2):185-201.

63. Kerr WC, Ye Y. Beverage-specific mortality relationships in US population data. Contemporary drug problems. 2011;38(4):561-78.

64. Dienes Z. Using Bayes to get the most out of non-significant results. Frontiers in psychology. 2014;5.

65. Ugrinowitsch C, Fellingham GW, Ricard MD. Limitations of ordinary least squares models in analyzing repeated measures data. Med Sci Sports Exerc. 2004;36(12):2144-8.

66. Overall JE, Tonidandel S. Robustness of generalized estimating equation (GEE) tests of significance against misspecification of the error structure model. Biometrical Journal. 2004;46(2):203-13.

67. Koper N, Manseau M. Generalized estimating equations and generalized linear mixed-effects models for modelling resource selection. Journal of Applied Ecology. 2009;46(3):590-9.

68. Hastie TJ, Tibshirani RJ. Generalized additive models: CRC Press; 1990.

69. Shumway RH, Stoffer DS. Time series analysis and its applications: Springer Science \& Business Media; 2013.

70. Shumway RH, Stoffer DS. Time series analysis and its applications: with R examples: Springer Science \& Business Media; 2010.

71. Wood S. Generalized additive models: an introduction with R: CRC press; 2006.

72. Chatfield C. The analysis of time series: an introduction: CRC press; 2013.

73. Zinszer K, Verma AD, Charland K, Brewer TF, Brownstein JS, Sun Z, et al. A scoping review of malaria forecasting: past work and future directions. BMJ Open. 2012;2(6).

74. Osborne JW. Improving your data transformations: Applying the Box-Cox transformation. Practical Assessment, Research \& Evaluation. 2010;15(12):1-9.

75. Taylor JM, Yu M. Bias and efficiency loss due to categorizing an explanatory variable. Journal of Multivariate Analysis. 2002;83(1):248-63.

76. Peter Ď, Silvia P, editors. ARIMA vs. ARIMAX-which approach is better to analyze and forecast macroeconomic time series? Proceedings of the 30th International Conference Mathematical Methods in Economics Karviná, Czech Republic; 2012.

77. Granger CW. Some recent development in a concept of causality. Journal of econometrics. 1988;39(1):199-211.

78. Arjas E, Eerola M. On predictive causality in longitudinal studies. Journal of Statistical Planning and Inference. 1993;34(3):361-86.

79. Li L, Wu Z, Liang LJ, Lin C, Zhang L, Guo S, et al. An intervention targeting service providers and clients for methadone maintenance treatment in China: a cluster-randomized trial. Addiction. 2013;108(2):356-66.

80. Landberg J, Norström T. Alcohol and Homicide in Russia and the United States: A Comparative Analysis. Journal of Studies on Alcohol and Drugs. 2011;72(5):723-30.

81. Lebo MJ, Weber C. An effective approach to the repeated cross-sectional design. American Journal of Political Science. 2015;59(1):242-58.

82. Patilea V, Raïssi H. Corrected portmanteau tests for VAR models with time-varying variance. Journal of Multivariate Analysis. 2013;116:190-207.

83. Brandt PT, Williams JT. Multiple time series models: Sage; 2007.

This article is protected by copyright. All rights reserved. 
84. Johansen S. Statistical analysis of cointegration vectors. Journal of economic dynamics and control. 1988;12(2):231-54.

85. Edward CN, Moran JR, Nelson JP. The long-run demand for alcoholic beverages and the advertising debate: A cointegration analysis. Advances in applied microeconomics. 2001;10:31-54.

86. Brunt TM. Monitoring illicit psychostimulants and related health issues: BOXPress; 2012.

87. Jandoc R, Burden AM, Mamdani M, Lévesque LE, Cadarette SM. Interrupted time series analysis in drug utilization research is increasing: systematic review and recommendations. Journal of Clinical Epidemiology. 2015;68(8):950-6.

88. Penfold RB, Zhang F. Use of Interrupted Time Series Analysis in Evaluating Health Care Quality Improvements. Academic Pediatrics.13(6):S38-S44.

89. Open Science Collaboration. An open, large-scale, collaborative effort to estimate the reproducibility of psychological science. Perspectives on Psychological Science. 2012;7(6):657-60.

90. Jeffreys H. Theory ofprobability. Oxford: Clarendon Press; 1961.

91. Dienes Z. Bayes Factor Calculator. Available from: http://www.lifesci.sussex.ac.uk/home/Zoltan Dienes/inference/Bayes.htm.

92. Christie J. Bayes Factor Calculator. R code 2011. Available from: http://www.lifesci.sussex.ac.uk/home/Zoltan Dienes/inference/bayesFactorCalc2.R.

93. Beard E, Dienes Z, Muirhead C, West R. Using Bayes factors for testing hypotheses about intervention effectiveness in addictions research. Addiction (Abingdon, England). 2016;111(12):2230-47.

94. Percival DB, Walden AT. Wavelet methods for time series analysis: Cambridge university press; 2006.

95. Bollerslev T. Generalized autoregressive conditional heteroskedasticity. Journal of econometrics. 1986;31(3):307-27.

96. Breiman L. Random forests. Machine learning. 2001;45(1):5-32.

97. Huitema BE, McKean JW, Laraway S. Time-series intervention analysis using ITSACORR: Fatal flaws. Journal of Modern Applied Statistical Methods. 2007;6(2):4.

98. McArdle JJ. Dynamic but structural equation modeling of repeated measures data. Handbook of multivariate experimental psychology: Springer; 1988. p. 561-614.

99. Duncan TE, Duncan SC. A latent growth curve modeling approach to pooled interrupted time series analyses. Journal of Psychopathology and Behavioral Assessment. 2004;26(4):271-8.

100. Dematos G, Boyd MS, Kermanshahi B, Kohzadi N, Kaastra I. Feedforward versus recurrent neural networks for forecasting monthly japanese yen exchange rates. Financial Engineering and the Japanese Markets. 1996;3(1):59-75.

101. Zeger SL, Irizarry R, Peng RD. On time series analysis of public health and biomedical data. Annu Rev Public Health. 2006;27:57-79.

102. Knudson C. 8 confint. glmm. Package 'glmm'. 2018:8.

103. Bates D, Maechler M, Bolker B, Walker S. Ime4: Linear mixed-effects models using Eigen and S4. $R$ package version. 2014;1(7):1-23.

104. Pinheiro J, Bates D, DebRoy S, Sarkar D. R Core Team (2014) nlme: linear and nonlinear mixed effects models. $\mathrm{R}$ package version 3.1-117. Available at $\mathrm{h}$ ttp://CRAN R-project org/package= nlme. 2014.

105. Maas CJ, Hox JJ. Sufficient sample sizes for multilevel modeling. Methodology. 2005;1(3):8692.

106. Snijders TA. Power and sample size in multilevel linear models. Encyclopedia of statistics in behavioral science. 2005.

107. Wood SN. mgcv: GAMs and generalized ridge regression for R. R news. 2001;1(2):20-5.

108. Wood S, Scheipl F. gamm4: Generalized additive mixed models using mgcv and Ime4. R package version 0.2-3. 2014.

109. Keele LJ. Semiparametric regression for the social sciences: John Wiley \& Sons; 2008. 
110. Hyndman RJ, Athanasopoulos G, Bergmeir C, Caceres G, Chhay L, O'Hara-Wild M, et al. forecast: Forecasting functions for time series and linear models. 2018.

111. Chan K-S, Ripley B. TSA: time series analysis. R package version 1.01. URL: http://CRAN Rproject org/package= TSA. 2012.

112. Pfaff B. VAR, SVAR and SVEC models: Implementation within R package vars. Journal of Statistical Software. 2008;27(4):1-32.

113. Di Narzo AF, Aznarte JL, Stigler M. Package 'tsDyn'. 2018.

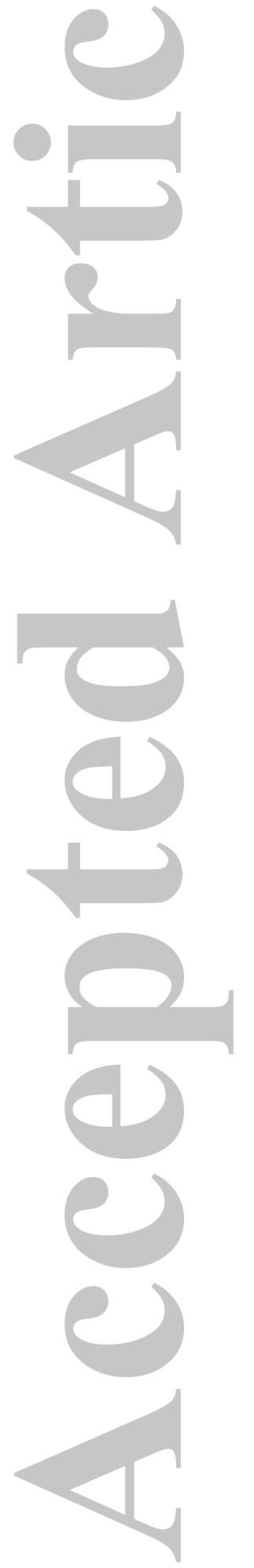

